\title{
Platform Optimization and Cost Analysis in a Floating Offshore Wind Farm
}

\author{
Alberto Ghigo *, Lorenzo Cottura, Riccardo Caradonna, Giovanni Bracco and Giuliana Mattiazzo \\ Department of Mechanical and Aerospace Engineering, Politecnico di Torino, C.so Duca degli Abruzzi, 24, \\ 10129 Turin, Italy; s263142@studenti.polito.it (L.C.); s266628@studenti.polito.it (R.C.); \\ giovanni.bracco@polito.it (G.B.); giuliana.mattiazzo@polito.it (G.M.) \\ * Correspondence: s265233@studenti.polito.it
}

Received: 9 September 2020; Accepted: 20 October 2020; Published: 23 October 2020

\begin{abstract}
Floating offshore wind represents a new frontier of renewable energies. The absence of a fixed structure allows exploiting wind potential in deep seas, like the Atlantic Ocean and Mediterranean Sea, characterized by high availability and wind potential. However, a floating offshore wind system, which includes an offshore turbine, floating platform, moorings, anchors, and electrical system, requires very high capital investments: one of the most relevant cost items is the floating substructure. This work focuses on the choice of a floating platform that minimizes the global weight, in order to reduce the material cost, but ensuring buoyancy and static stability. Subsequently, the optimized platform is used to define a wind farm located near the island of Pantelleria, Italy in order to meet the island's electricity needs. A sensitivity analysis to estimate the Levelized Cost Of Energy is presented, analyzing the parameters that influence it most, like Capacity Factor, Weighted Average Capital Cost (WACC) and number of wind turbines.
\end{abstract}

Keywords: offshore wind energy; marine renewable; floating offshore platform; hydrostatic analysis; wind farm; LCOE; cost analysis

\section{Introduction}

Wind energy is one of the most promising renewable sources of the last decade. The ample availability, large market potential, and cost competitiveness of the wind resource have allowed consistent technological development, in order to exploit its energy potential. Together with solar photovoltaics, wind is the protagonist in replacing traditional energy sources such as gas, oil, and coal, in order to reduce polluting and greenhouse gas emissions, based on the provisions of the 2015 Paris Agreement. The European Union has been an early mover on renewable energy and is committed to becoming the global leader in renewables. With almost 417 TWh of energy generated in 2019, wind energy made it possible to meet 15\% of European electrical energy needs [1]. All this is part of the European Union's ambitious project, called the Green New Deal, which by supporting the transition to the intensive use of renewable sources, utilizes the process of decarbonization and the elimination of greenhouse gas emissions by 2050 in Europe.

Alongside onshore wind, which has experienced rapid development in recent years, a great interest in offshore wind has been born. It is a technology that allows the installation of turbines directly in the open sea, fixed on the seabed, or floating, which therefore allows exploiting higher wind availability and potential. The offshore wind industry was launched in 1991 with the construction of the first offshore wind farm off the coast of Denmark with 11 turbines of $450 \mathrm{kw}$. The industry has continued to build on this technology which has naturally led to Europe being the leader in offshore wind power. Offshore wind has a growth rate of over $30 \%$, with a growth rate second only to solar photovoltaics, according to the Offshore Wind Outlook [2]. In 2019, 3.6 GW of offshore wind power 
was installed in Europe, confirming a trend of continuous growth and reaching an installed power of over 22 GW [3]. The countries that have invested most are the United Kingdom, Germany, Denmark, and Belgium.

The European Commission claims that Europe needs between 230 and $450 \mathrm{GW}$ of offshore wind by 2050, making it a crucial pillar in the energy mix together with onshore wind. Four-hundred-and-fifty gigawatts would meet $30 \%$ of Europe's electricity demand in 2050, which would have grown $50 \%$ compared to 2015 [4].

Currently, $90 \%$ of global installed offshore wind capacity is commissioned and operated in the North Sea and nearby Atlantic Ocean [5]. As visible from the wind atlas in Figure 1, the highest specific producibility is found in northern Europe, near the North Sea and the Baltic Sea. In fact, currently almost all of the wind farms are located there, and they are mostly fixed structures, as there are shallow seas. However, much of this potential is not exploited; moreover, in the Mediterranean Sea there is a good productivity, in particular along the Sicilian Channel and in the south of France [6]. In this case, however, as the depth of the sea can exceed $100 \mathrm{~m}$, it is necessary to resort to floating structures.

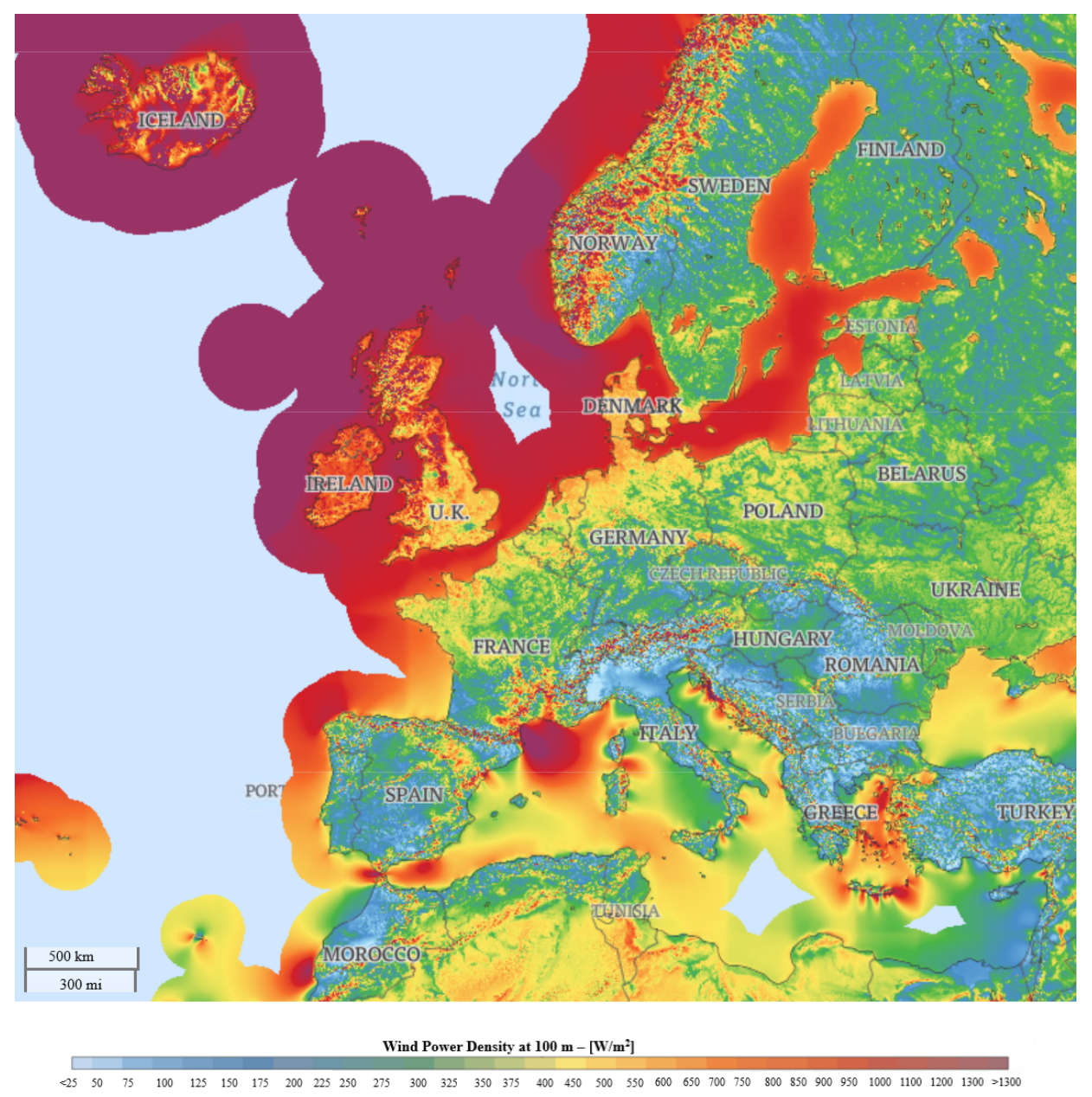

Figure 1. Wind Power Density at $100 \mathrm{~m}$, adapted from [6].

In particular, floating offshore wind platforms are the most encouraging among offshore structures, thanks to the numerous benefits they bring. In the first place they make possible to exploit large stretches of sea that are more than $60 \mathrm{~m}$ deep. Second, they ease turbine set-up, even for mid-depth conditions $(30-50 \mathrm{~m})$ and may in time offer a lower cost alternative to fixed foundations. In addition, floating foundations generally offer environmental benefits compared with fixed-bottom designs due to less invasive activity on the seabed during installation [5]. 
The construction of offshore wind farms requires considerably higher investments than onshore ones: the most significant cost items concern the construction of the platform and the turbine, and the subsequent installation, which often requires the use of large laying vessels, the laying of anchors and moorings, and the laying of electrical cables and electrical substations. Furthermore, even the control and maintenance interventions are more frequent, as it operates in a hostile marine environment. Consequently, offshore wind energy is currently more expensive than other forms of energy.

In 2018, the offshore wind outlook estimated a global Levelized Cost Of Energy (LCOE) of $\$ 140 / \mathrm{MWh}$, much higher than that estimated for onshore wind, of about $\$ 60 / \mathrm{MWh}$ [2]. However, the trend foresees a decrease in the coming years, as visible in Figure 2: in part this is due to continued improvements in manufacturing and turbine design, as well as improved capacity factors. In fact, the growth in turbine size helps to increase wind farm output: larger turbines with greater swept areas yield higher capacity factors for the same resource quality. Moreover, a decrease in financial costs related to investments, as project risk has declined, as well as in operation and maintenance costs has driven down the costs of wind power to reach a LCOE of around $\$ 60 / \mathrm{MWh}$ in 2040 and confirmed offshore wind as a key driver of the clean energy transition [2]. As regards floating offshore wind, the LCOE is actually greater, as a FOWT is more complex than a fixed system and more components are required. In [7], LCOE has been estimated for a wind farm on the basis of different concepts: in the case of Hywind's spar buoy the average LCOE is equal to $€ 164.6 / \mathrm{MWh}$, varying between $€ 243.4 / \mathrm{MWh}$ and $€ 109.3 / \mathrm{MWh}$, respectively, for best- and worst-case scenarios, while for Windfloat's semi-submersible is equal to $€ 189.2 / \mathrm{MWh}$, varying between $€ 287.8 / \mathrm{MWh}$ and $€ 120.5 /$ MWh.

\section{LCOE with trasmission}
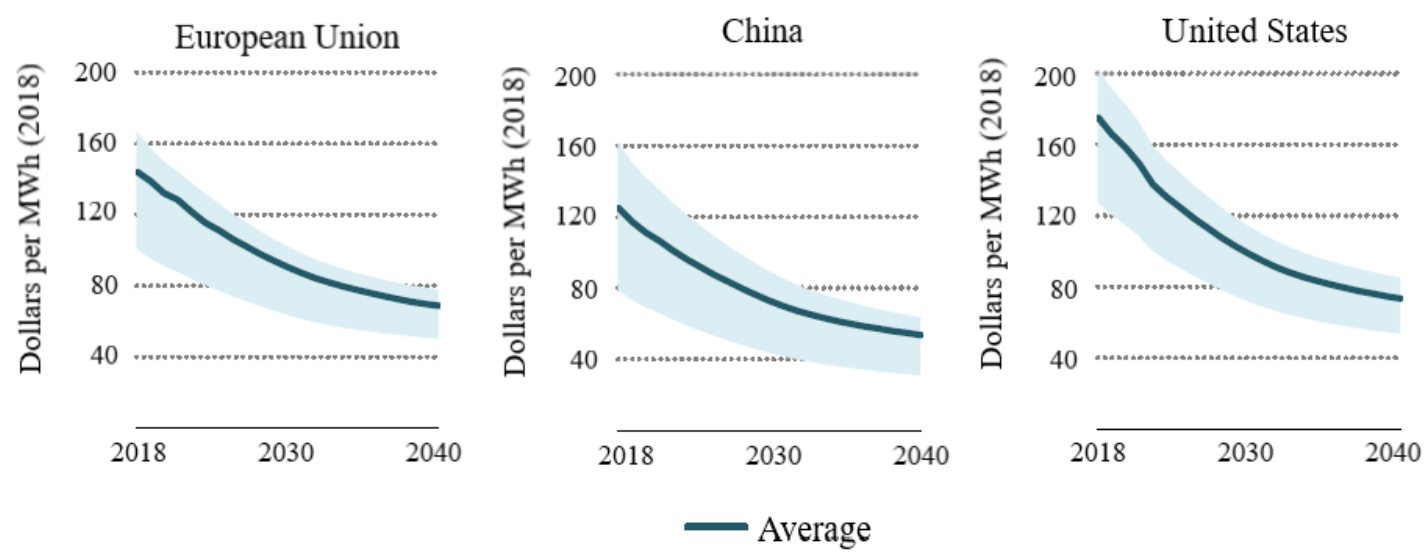

Figure 2. Levelized Cost Of Energy (LCOE) for new offshore wind projects in the European Union, China, and United States from 2018 to 2040, adapted from the work in [2].

In the last decade, some wind farms have been built and many projects are in progress. Hywind Scotland was the first pre-commercial wind farm built in the world: it consists of five spar-buoy structures supporting $6 \mathrm{MW}$ wind turbines, for a total installed power of $30 \mathrm{MW}$ [8]. Based on this success, Equinor has developed a new project, Hywind Tampen. The floating wind farm will consist of 11 wind turbines, for a total installed power of $88 \mathrm{MW}$, and will provide electricity for the Snorre and Gullfaks offshore field operations in the Norwegian North Sea. In the Atlantic Ocean, along the coast of Portugal, there is WindFloat Atlantic wind farm: developed by Principle Power, it includes three turbines installed on floating semi-sub foundations, with a total installed capacity of $25 \mathrm{MW}$ [9]. As for the Mediterranean Sea, France is the country that has invested the most in offshore wind. Based on the results obtained from the Floatgen Demonstrator [10], France's first offshore wind turbine installed in October 2018, the pre-commercial Eolmed Project will provide the development 
and construction of a $30 \mathrm{MW}$ offshore wind farm with three wind turbines, $15 \mathrm{~km}$ off the coastal town of Gruissan [11]. Not far away, in the Gulf of Lyon, a $30 \mathrm{MW}$ wind farm is expected to be installed by 2022, consisting of three semi-submersible platforms supporting $10 \mathrm{MW}$ wind turbines [12]. The project is led by Engie and EDP Renewables. Furthermore, the Provence Grand Large project is a pilot farm near Marseille, scheduled for 2021: it will consist of three wind turbines supported by semi-submersible structures for a cumulative power of $25 \mathrm{MW}$ [13].

\section{State of Wind Power in Italy}

Today, in Italy, about $10.7 \mathrm{GW}$ of onshore wind power is installed, mainly in the southern regions such as Puglia, Campania, and Basilicata, in addition to the islands such as Sardinia and Sicily, while there is no offshore installation. In 2019 the PNIEC, Integrated National Energy and Climate Plan had defined the ambitious goal of $300 \mathrm{MW}$ of installed offshore wind power by 2025, to then triple in 2030 [14]. Currently, the state-of-the-art is far from these objectives as there are officially no offshore wind farms. The project, which is in the most advanced state, that is the only one currently under construction, involves the construction of ten $3 \mathrm{MW}$ turbines off the port of Taranto [15]. The wind farm will be made of bottom-fixed structures, since water depths varies between 3 and $18 \mathrm{~m}$.

The first floating wind farm project involves the construction of a $250 \mathrm{MW}$ wind farm, consisting of 25 turbines of $10 \mathrm{MW}$ each, in the Sicilian channel, off the coast of Marsala, in one of the windiest areas of Italy [16]. The wind farm will not be visible from the Sicilian coast as it will be installed in the direction of Tunisia $40 \mathrm{~km}$ from the coast, in order to reduce the environmental impact and visual pollution. Another project instead involves the construction of a $504 \mathrm{MW}$ wind farm, consisting of 42 turbines of $12 \mathrm{MW}$ each, in the southwestern part of Sardinia, 35 chilometers from Portoscuso, in the province of Carbonia-Iglesias [17]. The project is currently undergoing administrative verification by the Italian Ministry of the Environment. Finally, a project involves the construction of a wind farm off the coast of Rimini. These are 59 fixed bottom structures, which will support 5.6 MW turbines, for a total of approximately $300 \mathrm{MW}$ of installed power.

Despite the high offshore potential available in Italy, there are several obstacles in the spread of offshore wind: first of all the need for large capital investments, given the high costs of construction and maintenance of the wind farms; second, the time required to obtain the authorizations, which often require a very long time for approval. Furthermore, as the largest specialized companies in the sector are foreign, a major obstacle is the lack of a local supply chain capable of supporting the construction and development of new wind farms.

The scope of this work is to investigate different floating platform concepts, in order to define a new design that satisfy constraints imposed by actual Standards, to optimize main dimensions and to reduce material costs. The aim is to define and study an Italian offshore wind farm, in order to evaluate the feasibility of the project and the main economic parameters, like the LCOE.

\section{Approach}

This work is based on the use of an in-house hydrostatic tool that, after the definition of five different floating substructures, permits to calculate main hydrostatic parameters, in order to allow a quick verification of the platform static stability. The working principle is reported in Figure 3.

For each platform concept that has been defined by recurring to commercial project data or literature documents, the tool allows calculating weights and volumes. By the application of Archimedes' principle, it is possible to determine the submerged volume and draught. Then, after choosing the typology of the turbine, NREL $5 \mathrm{MW}$ or DTU $10 \mathrm{MW}$, the program estimates the coordinates of the center of gravity (COG) and the center of buoyancy (COB).

The first hydrostatic parameter of great relevance is the metacentric height: if it is greater than zero the system could be considered stable; otherwise, it is unstable, and the geometry and weight distribution must be modified. Then, the tool allows calculating the hydrostatic stiffness in heave, roll, and pitch, and, by the application of a generic thrust force that acts on the center of the rotor, the 
maximum inclination angle in pitch. In order to verify the validity of the program, the obtained results were compared with those obtained by Ansys Aqwa.

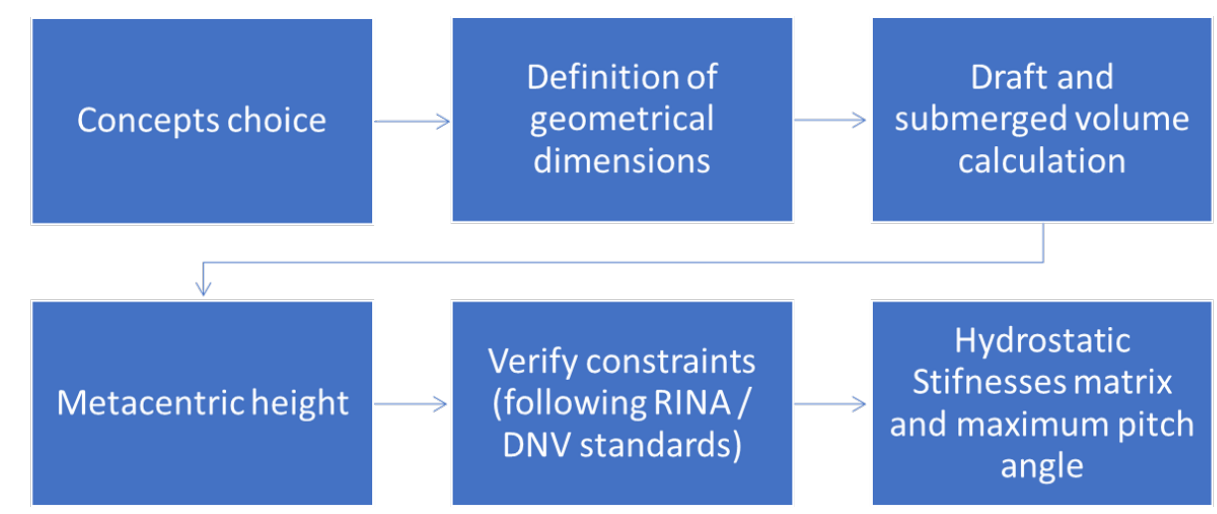

Figure 3. Operating scheme of the hydrostatic tool.

Then, the tool has been implemented to perform an optimization with Matlab genetic algorithm: the purpose is to identify the best concept in terms of weight and material cost among all the platforms, which nevertheless satisfies the constraints imposed by Standards. Once the main material costs have been estimates from literature, for each concept has been defined a material cost function, that is the fitness function to minimize. From the results obtained, it has been possible to identify two most promising concepts - the Spar-buoy and Hexafloat—with whom a preliminary project has been defined for a wind farm near the island of Pantelleria. Finally, a sensitivity analysis identifies possible cost reductions due to an increase in capacity factor, a decrease in Weighted Average Capital Cost (WACC), or by varying the number of turbines and rating.

\section{Concepts Review}

Floating substructures are usually classified according to how they achieve static stability. The wind acting on the turbine generates an aerodynamic thrust that tends to incline the whole platform, and thus the platform must generate a moment which counteracts this effect, also called the restoring moment.

The spar design is characterized by a steel or concrete cylinder with low water plane area, ballasted with water or solid ballast to keep the center of gravity below the center of buoyancy. Spars are stable in general, due to the large draft.

The semi-submersible and barge configuration achieves the necessary static stability mainly by exploiting the buoyancy force: to obtain this effect a large waterplane area is necessary.

The Tension Leg Platform (TLP) is a structure with large buoyancy that is restrained by means of a tension leg mooring system. These legs are usually cables and, when inclined, the higher tension in the windward leg compared with in the leeward leg creates a restoring moment, which counteracts the inclining moment due to the wind [18].

A graphic representation of the main types of floating platforms is shown in Figure 4.

In this work, five platform concepts have been investigated: two concepts are technologically mature and have been developed in pre-commercial wind farm (HyWind's spar-buoy and Windfloat's semi-submersible); one has been experimentally tested with a prototype in open sea, but not yet commercialized (Hexafloat by Saipem S.A.); one has been defined only from a theoretical point of view (Sea Flower by Fincantieri); and the last one is still in a state of preliminary definition.

Sea Flower is a floating offshore wind platform designed by Fincantieri Offshore. It consists of a hexagonal submerged platform acting as main buoyant body and six semi-submerged columns at the corner. The entire structure is made of low-weight concrete. The platform can be moored with a six-line mooring system to the seabed and it is suitable for sea depth of 50-200 m. The structure's 
stability allows small inclination angles and therefore an excellent exposure to winds, ensuring greater energy generation effectiveness [19].

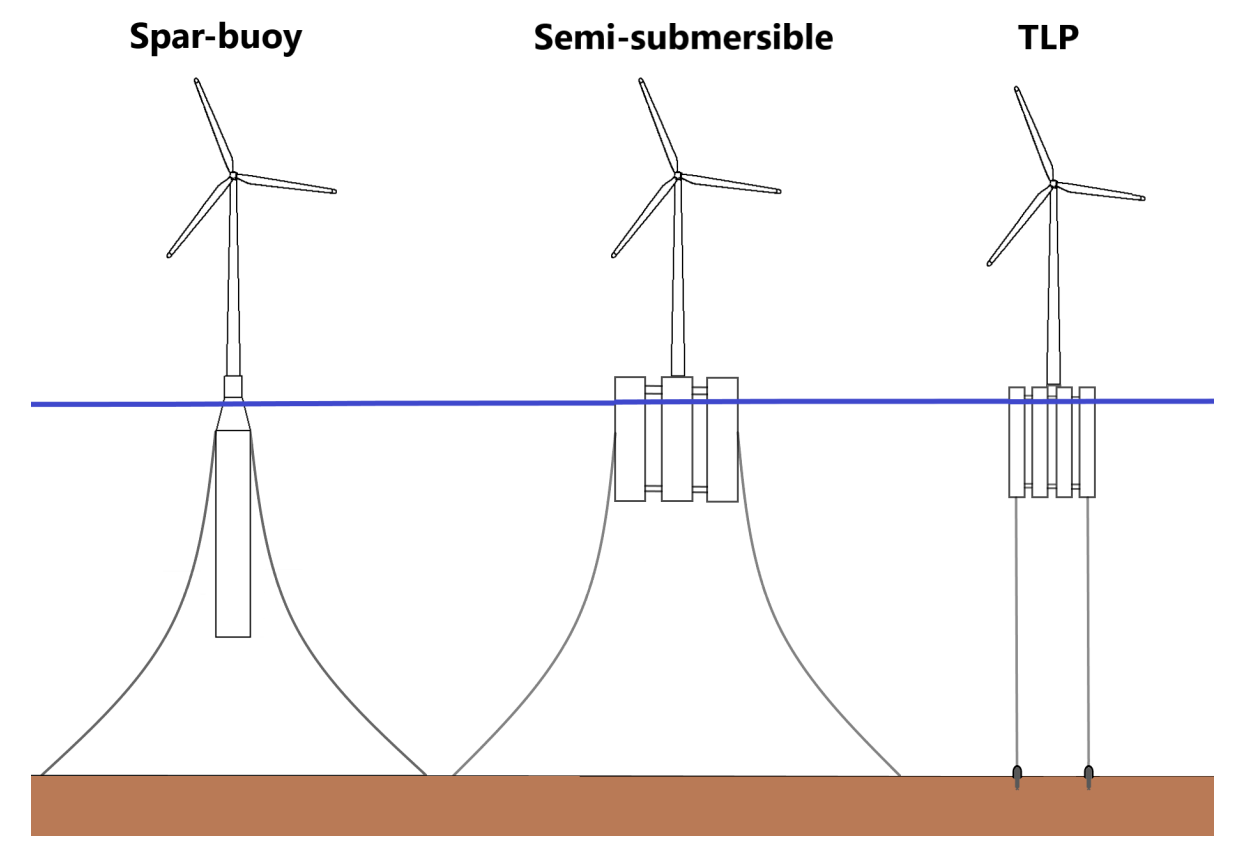

Figure 4. Floating offshore wind farm foundations with according stabilization principle.

The second concept analyzed is the WindFloat platform, developed by Principle Power, as part of the WindFloat Atlantic project. The substructure is a semi-submersible concept, consisting of three cylindrical-shaped columns in a triangular alignment. The columns are interconnected by horizontal bracing beams, forming a truss structure. Each column is equipped with horizontal heavy plates at the lower part of the column, so as to increase the added mass in heave, in order to reduce the global platform motion. The turbine tower is installed on one of the three columns. The diameter of the tower base should be close to the column diameter to allow the best possible continuity of the structure and to reduce the stress concentration [20].

The third concept is the Hywind platform, developed by Equinor (Statoil), as part of the HyWind Scotland project. The substructure is a spar-buoy concept, consisting of a cylindrical-shaped column. It is a hollow structure made of steel and it is characterized by ballast material made of generic concrete and sea water, to guarantee stability and low inclination angle in pitch even in the presence of high waves and strong winds. The steel weight is 2300 tonnes and, when the structure is ballasted, the total weight of platform and turbine is around 10,000 tonnes. The structure is anchored to the seabed by three mooring chains, each connected to a suction anchor [8].

The fourth concept is the Hexafloat platform, developed by Saipem SA. The floating substructure is a pendulum floater linked with six tendons connected to a counterweight. The floater is an hexagonal shape structure of steel cylinders, with a central column that supports the wind turbine. The counterweight is made of steel and will be shaped as a cylinder in order to accommodate the ballast inert material: in this work, magnetite is considered as the material for the counterweight, that is, iron powder with a density of $5200 \mathrm{~kg} / \mathrm{m}^{3}$. The structure needs from three to six mooring lines, typically composed by chain or taut-leg moorings and a drag anchor for each line. The main advantage of this concept is that the diameter of the tubular structure could be slightly adapted and the ballast depth could be adjusted to suit different turbine sizes, from 2 up to $15 \mathrm{MW}$. Otherwise, the overall dimensions of the structure will remain similar regardless of turbine size. That could make it easier to move towards serial manufacturing of the substructure, helping to reduce the Levelized Cost Of Energy [21]. This substructure is relatively newer if compared to the others concepts: patented 
in December 2018, it is involved in the Aflowt project (2019-2022), during which a full-scale floating turbine will be built and tested in the northern part of Ireland [22].

The last concept, called New Concept, is a new platform and it is not involved in any project. The design comes from the Hexafloat structure, with some changes to reduce the steel weight of the platform: in particular, all lateral brackets have been removed. The floater is a hexagonal shape structure of steel cylinders, with a central column that supports the wind turbine. Like the previous structure, there is a counterweight so as to accommodate the ballast inert material. The ballast depth can be adjusted to suit different turbine sizes.

The TLP structure was not considered as there is already an experimental prototype built and installed in Southern Italy: Blue $\mathrm{H}$ has launched and validated a prototype off the coast of Brindisi, at the end of 2007 [23]. Consequently, it was preferred to focus on the spar and semi-submerged structures.

All the concepts previously introduced are shown in Figure 5.

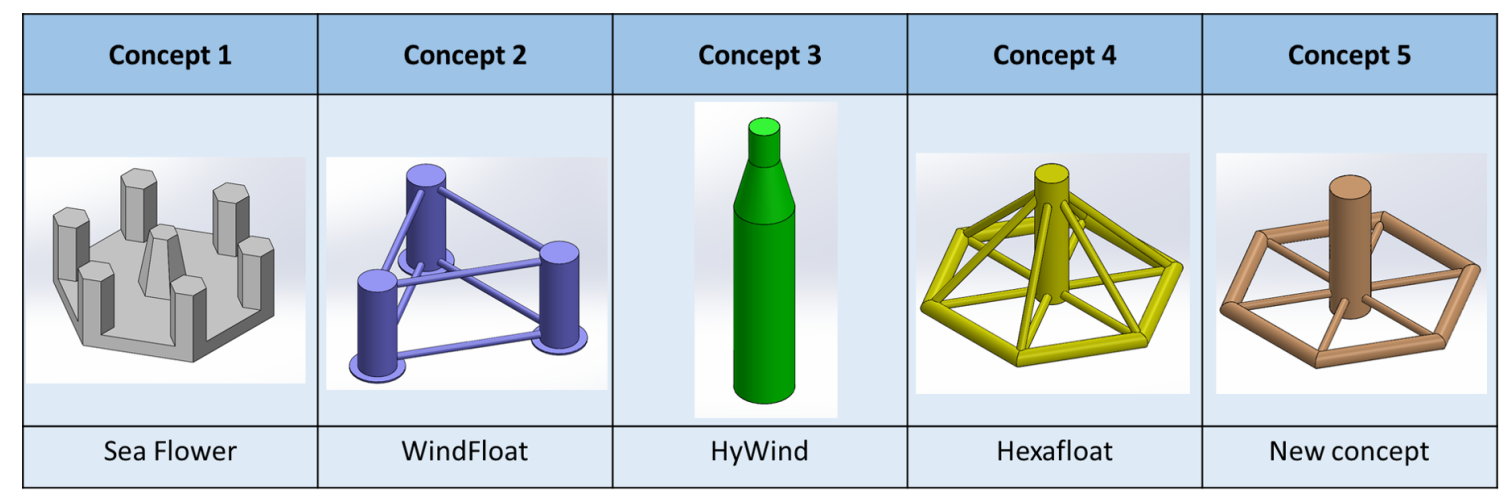

Figure 5. Platform concepts under study.

\section{Hydrostatic Analysis}

After the definition of the most important features for each concept, the tool focuses on the floatability of the complete FOWT, consisting of the platform and the turbine. The forces acting on the system and the main hydrostatic parameters that contribute in defining the static stability are reported below.

\subsection{Gravitational and Buoyancy Force}

The floating equilibrium is achieved by balance between the weight of the system and the buoyancy force. The buoyancy force derives from Archimedes' principle, saying that any object which is partially or fully immersed in a fluid is buoyed up by a force equal to the weight of the fluid that the body displaces. The weight of the displaced volume is equal to the multiplication between the volume, the density of the fluid, and the gravitational acceleration. Mooring forces were not considered at this preliminary stage. Equation (1) shows the relation between the buoyancy force $F_{B}$ and the weight of the system $F_{G}$, that act in opposite directions:

$$
F_{B}-F_{G}=\rho_{\mathrm{w}} g V-m g=0
$$

the weight of the system comprises the substructure, including steel and ballast material like water or concrete, and the turbine. Once the total weight is known, it is possible to estimate the submerged volume, knowing that $\rho_{\mathrm{w}}$ is the sea water density is $1025 \mathrm{~kg} / \mathrm{m}^{3}$ and $\mathrm{g}$ is the gravity acceleration, assumed $9.81 \mathrm{~m} / \mathrm{s}^{2}$.

The next step consists of the center of gravity calculation. The overall center of mass, or COG, can be determined by the sum of the single mass times their position, divided by the sum of masses. All the concepts are symmetric, so only the vertical position along $\mathrm{z}$-axis of the center of mass should be estimated. Equation (2) shows how the vertical position of the center of mass can be calculated. 
The index $n$ indicates the different part of the system, $z$ is the coordinate along vertical, $z_{n}$ is the position of COG of a specific part, and $d m_{n}$ is the mass of a specific part.

$$
C O G_{z}=\frac{\sum_{i=1}^{n} z_{n} d m_{n}}{\sum_{i=1}^{n} d m_{n}}
$$

The position of the buoyancy force is determined by the center of mass of the displaced fluid, in this case sea water. The center of buoyancy is defined as the multiplication between the volumetric center of each submerged part and the submerged volume, divided by the total volume displacement. This is shown in Equation (3) for the center of buoyancy in the vertical direction along z-axis. Index $n$ denotes the submerged parts of the structure, $d V_{n}$ is the volume of a specific part, and $z_{b n}$ is the coordinate for the volumetric center of the part.

$$
\mathrm{COB}_{z}=\frac{\sum_{i=1}^{n} z_{b n} d V_{n}}{\sum_{i=1}^{n} d V_{n}}
$$

\subsection{Metacentric Height}

Stability is defined as the ability of a system to manage disturbances, like waves, current, and wind. The most significant parameter of static stability is the metacentric height, denoted as GM, that is defined as the distance between the center of gravity and the metacenter [24]. In Figure 6, there is a representation of a transverse section of a floating body. In particular, $G$ is the center of gravity, $\mathrm{B}$ is the center of buoyancy, $\mathrm{K}$ is the keel of the structure, and $\mathrm{M}$ is the metacenter. The metacenter is a fictive point located at the intersection between the center line of the structure and a vertical line from the center of buoyancy.

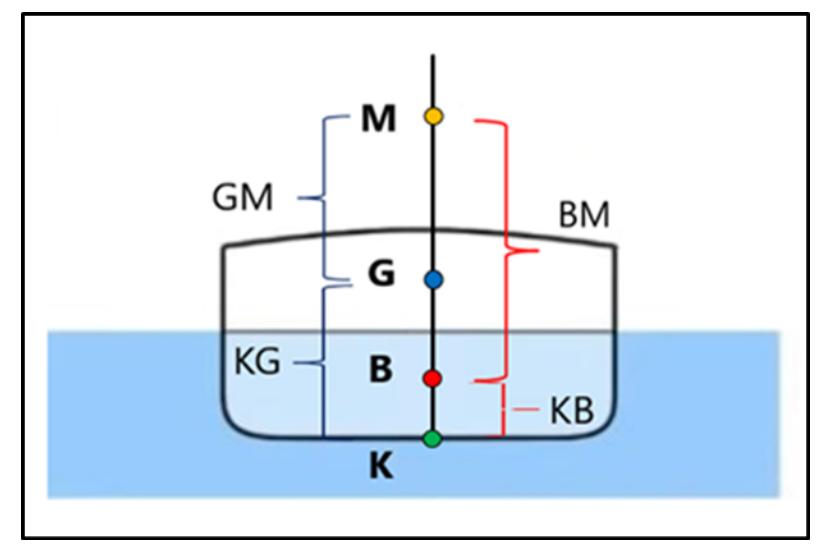

Figure 6. Metacentric height.

If metacentric height is positive, the floating body is characterized by initial static stability and in the presence of disturbing forces it returns in the original position. On the other hand, if the metacentric height is negative, the structure is not able to return to the original position and continues to turn over. Consequently, the structure is unstable and must be modified. The standard DNVGL-OS-C301 establishes that for spar concept the metacentric height must be superior to one meter, in order to guarantee sufficient static stability [25]. For small heel angles, less than 10 degrees, GM is assumed to be constant and is given by Equation (4):

$$
G M=B M+K B-K G
$$

where $B M$ is the distance from the metacenter to $C O B$, also called metacentric radius, and it is given by Equation (5); $K B$ is the distance from the keel to $C O B$; and $K G$ is the distance from the keel to the COG. 
The metacentric radius can be calculated by

$$
B M=\frac{I}{V}
$$

where $I$ is the second moment of area of the water plane area and $V$ is the displaced volume of the structure. Second moment of area, often called moment of inertia is given by Equation (6):

$$
I=\int_{A} x^{2} d A=I_{0}+d^{2} A
$$

The term $I_{0}$ describes the moment of inertia of an element with the reference axis in its centroid; the second term is the Steiner's contribution and comes from the offset between the actual center point and the part considered.

\subsection{Hydrostatic Stiffnesses}

The following step consists of the definition of the hydrostatic matrix, in which the most significative stiffnesses are heave, roll, and pitch. The hydrostatic stiffness in heave is shown in Equation (7):

$$
C_{33}=\rho_{\mathrm{w}} g A_{w l} \quad[\mathrm{~N} / \mathrm{m}]
$$

where $\rho_{\mathrm{w}}$ is the sea water density, assumed as $1025 \mathrm{~kg} / \mathrm{m}^{3} ; g$ is the gravity acceleration, assumed as $9.81 \mathrm{~m} / \mathrm{s}^{2}$; and $A_{w l}$ is the water line area of the structure.

The hydrostatic stiffness in roll, along the $x$-axis, is shown in Equation (8):

$$
C_{44}=\rho_{\mathrm{w}} g V \cdot G M \quad[\mathrm{Nm} / \mathrm{rad}]
$$

where $\rho_{\mathrm{w}}$ is the sea water density, $g$ is the gravity acceleration, $V$ is the submerged volume, and GM is the metacentric height.

The hydrostatic stiffness in pitch, along y-axis, is shown in Equation (9):

$$
C_{55}=\rho_{\mathrm{w}} g V \cdot G M \quad[\mathrm{Nm} / \mathrm{rad}]
$$

where $\rho_{\mathrm{W}}$ is the sea water density, $g$ is the gravity acceleration, $V$ is the submerged volume, and GM is the metacentric height. If the platform structure is symmetric, the hydrostatic stiffnesses $C_{44}$ and $C_{55}$ are equal because the metacentric height is the same.

The hydrostatic stiffness matrix is thus constituted, as can be seen from Table 1 .

Table 1. Hydrostatic stiffness matrix.

\begin{tabular}{lccc}
\hline & Heave (Z) & Roll (RX) & Pitch (RY) \\
\hline Heave (Z) & $C_{33}$ & & \\
\hline Roll (RX) & & $C_{44}$ & \\
\hline Pitch (RY) & & & $C_{55}$ \\
\hline
\end{tabular}

\subsection{Maximum Static Pitch Angle}

Another important aspect to consider is the effect of the wind that acts on the turbine, causing the inclination of the tower and a decrease in energy productivity. If it is considered as a simple one-dimensional (1-D) model for an ideal rotor [26], the aerodynamic thrust is the force in the streamwise direction resulting from the pressure drop over the rotor and can be expressed as

$$
T=\frac{1}{2} \rho_{\mathrm{w}} v^{2} A c_{t}
$$


where $\rho_{\text {air }}$ is the air density, $\mathrm{v}$ is the wind speed, $A=\pi R^{2}$ is the area of the rotor, and $c_{t}$ is the thrust coefficient. Through the data available on the respective sites, that provides the thrust coefficient $c_{t}$ for each wind speed, it has been possible to obtain the thrust and power curve for each wind turbine, NREL 5 MW and DTU 10 MW, as reported in Figure 7.

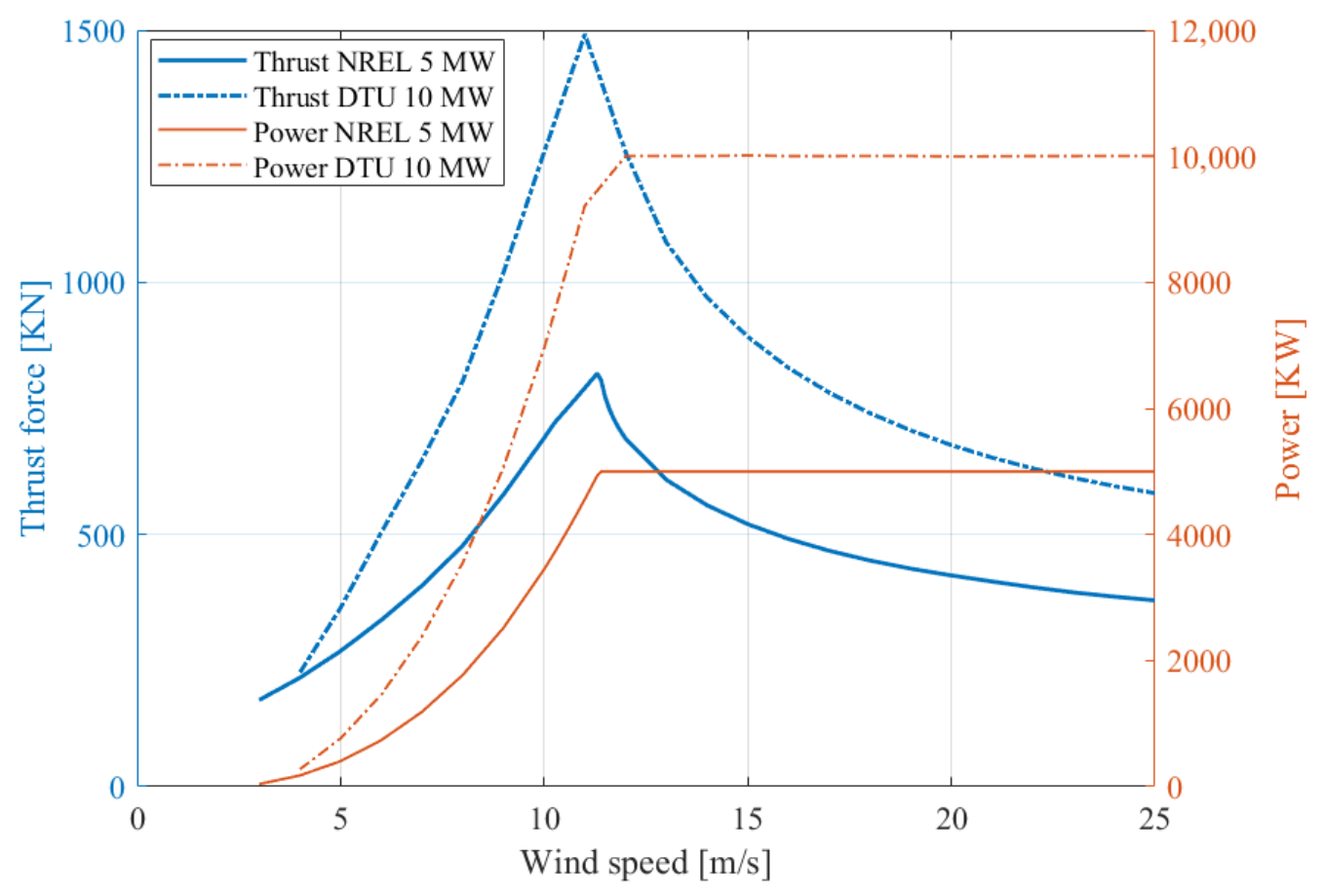

Figure 7. Thrust and power curves for NREL $5 \mathrm{MW}$ and DTU $10 \mathrm{MW}$ wind turbines.

The thrust force, acting on the rotor, is responsible of an overturning moment that acts on the center of buoyancy and that the platform must be able to counter. As this is a preliminary study, deformation is neglected.

The moment thrust can be expressed as

$$
M_{\text {thrust }}=F_{\text {thrust }} \cdot d
$$

where $d$ is the distance between the center of rotor and the COB, as reported in Figure 8. The thrust force considered for each turbine is the maximum of the thrust curve, so as to be more precautionary.

The maximum static pitch angle is obtained by dividing the moment thrust by hydrostatic pitch stiffness $C_{55}$ :

$$
\alpha_{\text {maximum pitch }}=\frac{M_{\text {thrust }}}{C_{55}}
$$

The standard DNVGL-OS-C301 reports that intact inclination angle is limited to $6^{\circ}$ and $12^{\circ}$ for normal operating conditions and survival conditions [25]. 


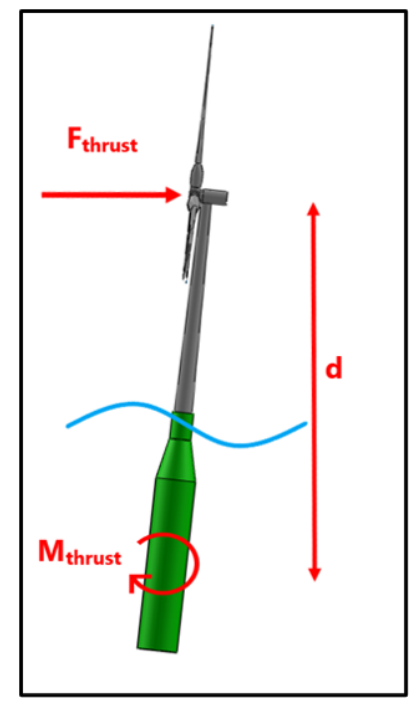

Figure 8. Thrust moment and force acting on the floating platform.

\section{Optimization through Matlab Genetic Algorithm}

The hydrostatic tool previously developed has been implemented with genetic algorithm by Matlab, in order to find the best concept in terms of weight and material cost.

A genetic algorithm (GA) is a method for solving both constrained and unconstrained optimization problems based on a natural selection process that mimics biological evolution. The algorithm repeatedly modifies a population of individual solutions. At each step, the genetic algorithm randomly selects individuals from the current population and uses them as parents to produce the children for the next generation. Over successive generations, the population "evolves" toward an optimal solution.

The generic syntax of Matlab genetic algorithm has the following form [27],

$\mathrm{x}=\mathrm{ga}(\mathrm{fun}, \mathrm{nvars})$

where ga finds a local unconstrained minimum, $x$; to the fitness function, fun; and nvars is the number of design variables of fun. In the considered case, the syntax changes to

$$
[x, f \text { fval }]=\operatorname{ga}(\text { fun }, \text { nvars },[],[],[],[], l b, u b, \text { nonlcon })
$$

where fun represents the fitness function to be minimized, nvars is the number of variables present in fun, LB and UB defines a set of lower and upper bounds on the design variables, $x$, so that a solution is found in the range $\mathrm{lb} \leq \mathrm{x} \leq \mathrm{ub}$ and nonlcon is a Matlab function that contains nonlinear constraints. The function nonlcon accepts $x$ and returns two vectors $C$ and Ceq, representing the nonlinear inequalities and equalities, respectively. The solver ga minimizes the function fun such that $C(x) \leq 0$ and $C e q(x)=0$. Finally, fval is the value of the fitness function at $x$. In order to find minimum of function using genetic algorithm, the following steps are required.

1. Problem definition and variables identification.

2. Coding the fitness function.

3. Coding the constraint function.

4. Minimizing the fitness function using ga.

In this study, genetic algorithm is used to minimize the material cost function for each floating platform and to identify the lightest and least expensive structure. The iterative process is illustrated in Figure 9 below. 


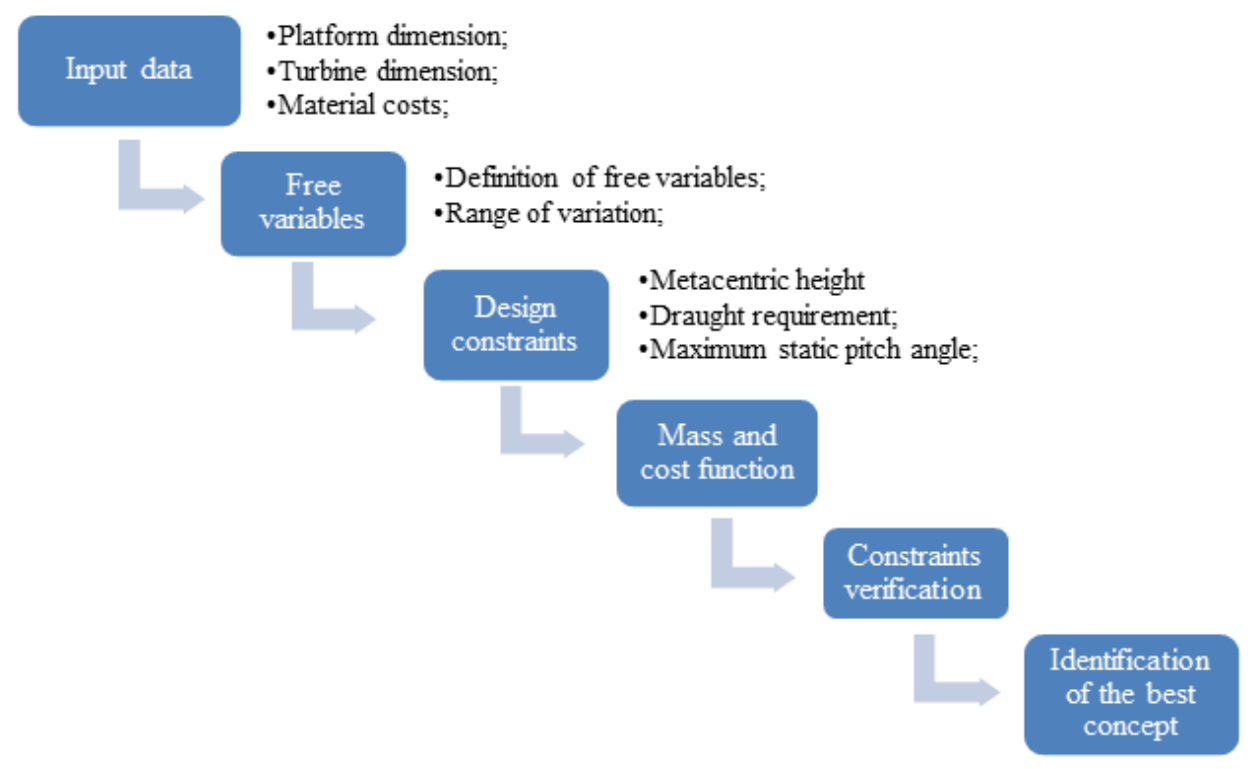

Figure 9. Genetic algorithm process.

The first step of the process provides for the identification of free variables for each concept: it is about those quantities, such as platform radius, column height, and mass of ballast, which intrinsically characterize a structure. Furthermore, to avoid unfounded or out-of-scale solutions, the variation ranges are defined for each of them. Constraints and requirements, concerning stability and buoyancy of the FOWT system are imposed, in accord to actual standards. Finally, for each concept a mass and a cost function are defined. In particular, the cost function works as a fitness function for genetic algorithm: for each cycle, genetic algorithm provides to minimize the cost function in order to satisfy all the constraints. The process evolves until the value of the cost function no longer decreases, as a minimum value has been reached. This process is repeated separately for each type of platform and subsequently by their comparison it is possible to identify the best concept in terms of material cost.

\subsection{Free Variables Definition}

For each design, free variables were identified among the dimensions that most distinguished a certain concept, such as height, diameter, amount of solid ballast, and sea water. Moreover, a range of variation has been defined for each variable, in order to allow the algorithm to cycle and obtain reasonable results, comparable with the existing structures.

For example, in the Spar-buoy design, four variables have been considered, as reported in Figure 10b.

- Platform diameter.

- Platform height.

- Ballast height.

- Sea-water height.

Instead, in the Hexafloat design, due to the fact that the geometry was completely different, the following parameters have been considered, as reported in Figure 10b.

- Central column diameter.

- Platform height.

- Hexagone radius.

- Ballast mass.

- Ballast distance above sea level. 


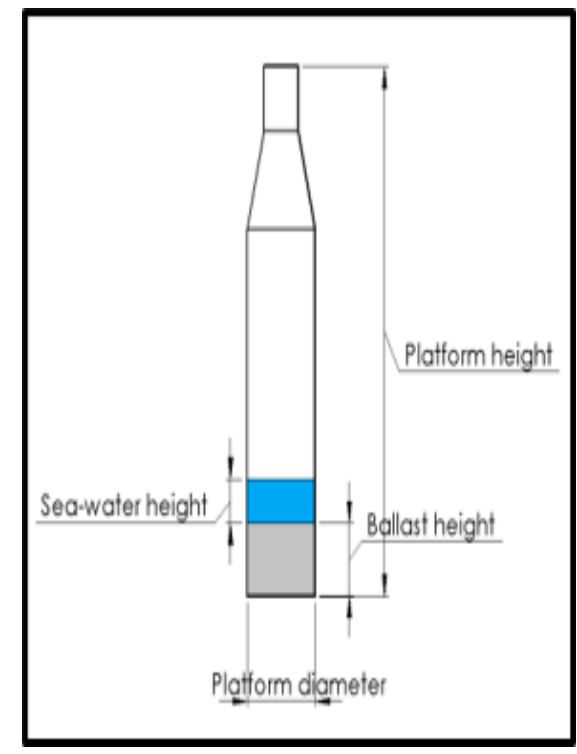

(a) Spar-buoy design

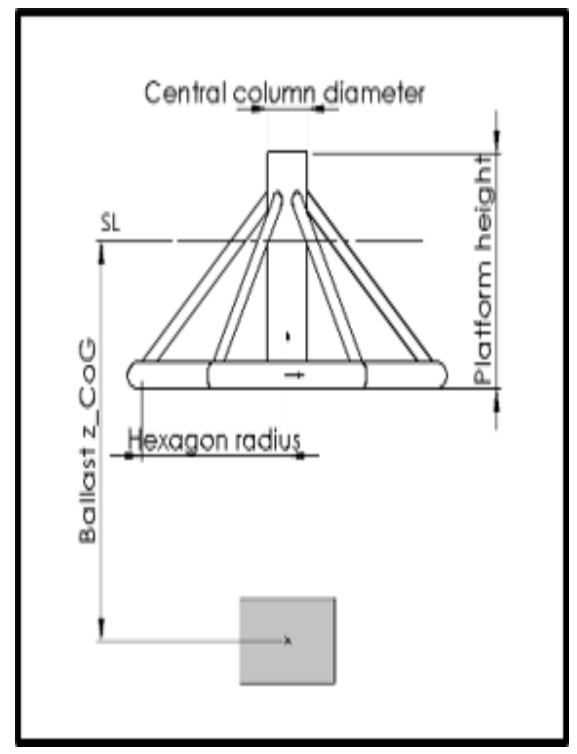

(b) Hexafloat design

Figure 10. Free variables in the genetic algorithm.

\subsection{Material Cost}

A very important aspect in a floating platform design is the material cost, by the fact that the size of the structure is imposing, this cost item must be considered. Today, platform structures are made of steel or concrete. The main material costs considered are shown in Table 2.

Table 2. Materials cost.

\begin{tabular}{lccc}
\hline Material & $\begin{array}{c}\text { Density } \\
{\left[\mathbf{k g} / \mathbf{m}^{3}\right]}\end{array}$ & $\begin{array}{c}\text { Cost } \\
{[€ / \text { ton] }}\end{array}$ & Source \\
\hline S355 steel & 8500 & 3000 & InnWind.Eu D4.33 [28] \\
\hline Concrete & 600 & 600 & Fincantieri [19] \\
\hline Generic ballast & 2500 & 70 & InnWind.Eu D4.33 [28] \\
\hline Magnetite (iron powder) & 5200 & 100 & Statista.com [29] \\
\hline
\end{tabular}

With regard to S355 naval steel, the original density of $7850 \mathrm{~kg} / \mathrm{m}^{3}$ has been incremented to $8500 \mathrm{~kg} / \mathrm{m}^{3}$ in order to consider the presence of flanges and welds, that otherwise would have been overlooked.

\subsection{Design Constraints}

For the preliminary design of the structure, a set of requirements are made to achieve floating equilibrium, static stability, and to ensure that the structure does not exceed allowable dimensions. The initial requirements are stated in four points.

- Metacentric height must be higher than $1 \mathrm{~m}$.

- Minimum draught of $10 \mathrm{~m}$ is required.

- $\quad$ Freeboard height must be larger than $5 \mathrm{~m}$.

- $\quad$ Maximum static pitch angle must be less than $5^{\circ}$.

Metacentric height greater than $1 \mathrm{~m}$ is required for deep draught floaters such as spars in DNVGL-ST-0119 Standard [30], and it is used as a requirement for the semi-submersible in this project as well. The draught requirement was set as $10 \mathrm{~m}$ in order to avoid slamming loads, as reported in [31]. Freeboard height has been considered in order to prevent the turbine tower from being at sea 
level, to avoid corrosion phenomena that could damage it quickly. The maximum static pitch angle falls within the constraints imposed by Standard, as illustrated in [25].

\subsection{Material Cost Function}

The material cost function is the fitness function, which is optimized through Matlab genetic algorithm. The cost function is defined as the sum of different material weight per cost material:

$$
f_{\text {cost }}=m_{\text {steel }} \cdot c_{\text {steel }}+m_{\text {concrete }} \cdot c_{\text {concrete }}+m_{\text {ballast }} \cdot c_{\text {ballast }}
$$

where $m$ is the mass and $c$ is the cost for each type of material of the concept considered.

\section{Results}

The main results of the iterative process generated by genetic algorithm is reported in the following pictures. In Figure 11 a comparison in terms of material cost for each platform design is reported, both for $5 \mathrm{MW}$ wind turbine and $10 \mathrm{MW}$ wind turbine. In Figure 12, a comparison in terms of weight is reported.

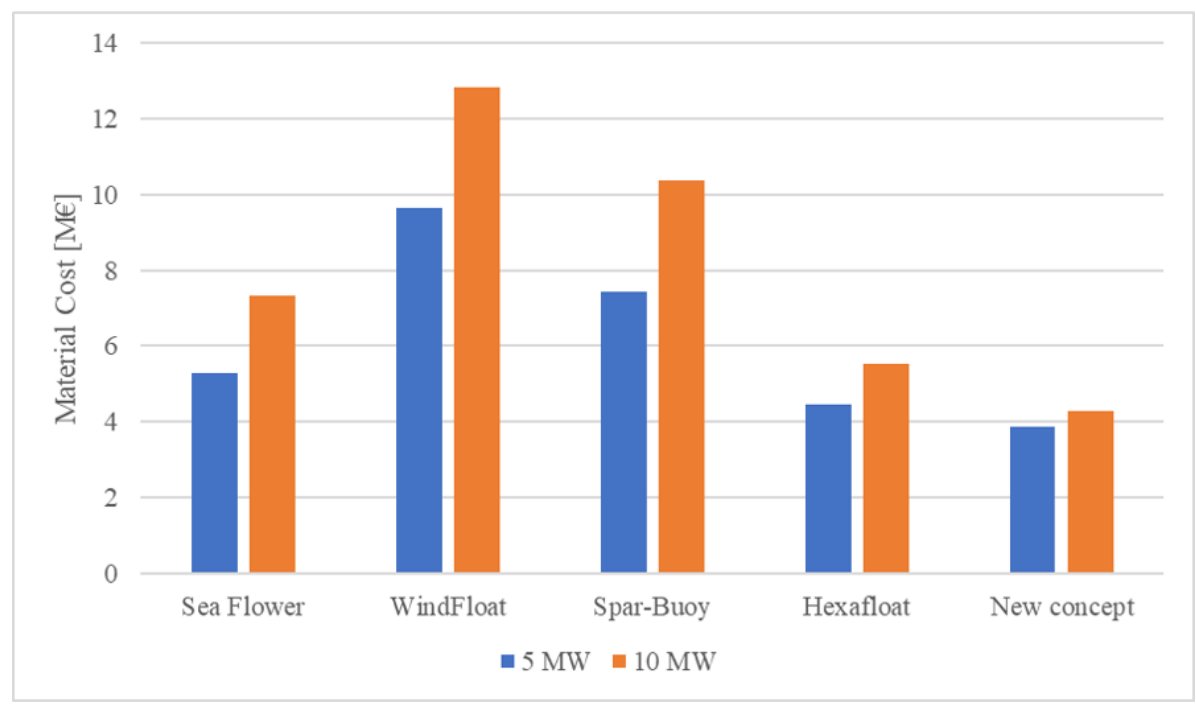

Figure 11. Comparison between the different concepts in terms of material cost.

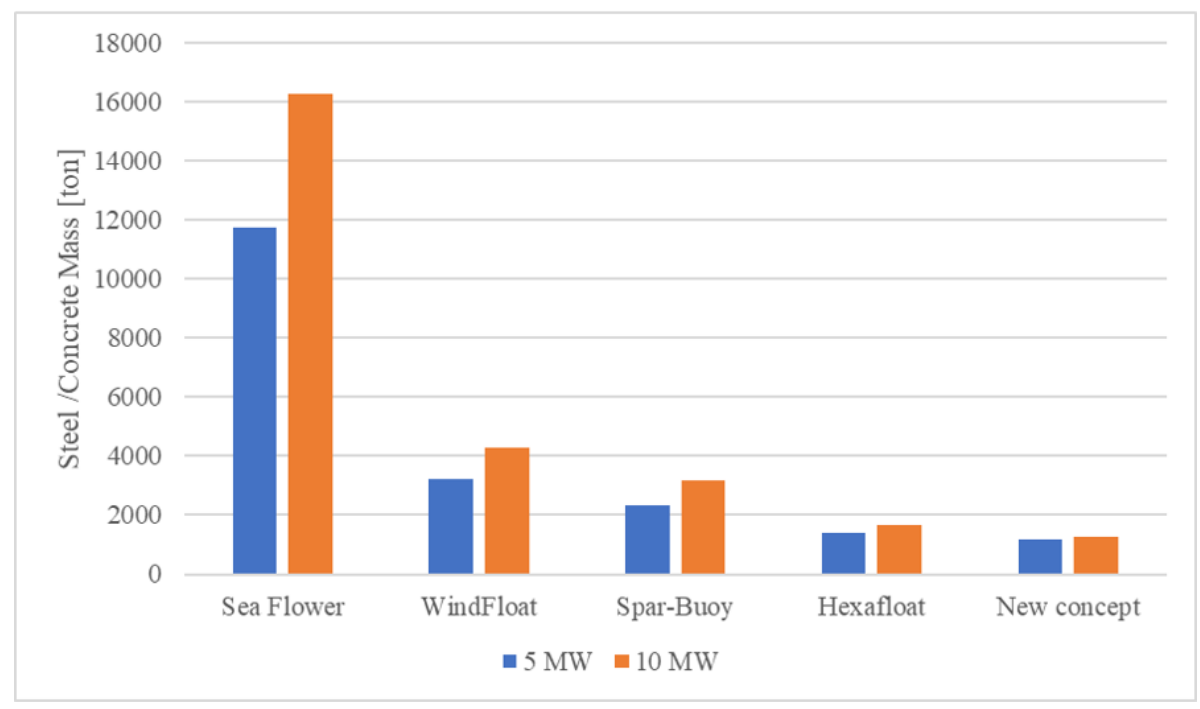

Figure 12. Comparison between the different concepts in terms of mass. 
All the concepts under study are made of steel, except for Sea Flower that is made of concrete.

\section{Best Concepts}

On the basis of the previous results, two concepts have been considered: among existing projects the spar buoy design by Equinor and among new developing projects the Hexafloat by Saipem. Their optimized values are summarized in Tables 3 and 4 .

Table 3. Dimensions and main hydrostatic parameters for Spar-buoy design.

\begin{tabular}{lcc}
\hline Spar-Buoy & \multicolumn{2}{c}{ Optimized Value } \\
\hline Wind turbine & NREL 5 MW & DTU 10 MW \\
\hline Platform diameter & $14.75 \mathrm{~m}$ & $15.91 \mathrm{~m}$ \\
\hline Platform height & $88.00 \mathrm{~m}$ & $111.17 \mathrm{~m}$ \\
\hline Concrete ballast height & $15.64 \mathrm{~m}$ & $24.06 \mathrm{~m}$ \\
\hline Seawater height & $17.85 \mathrm{~m}$ & $15.07 \mathrm{~m}$ \\
\hline Steel mass & $2.323 \times 10^{7} \mathrm{~kg}$ & $3.178 \times 10^{7} \mathrm{~kg}$ \\
\hline Material cost & $7.43 \mathrm{M} €$ & $10.36 \mathrm{M} €$ \\
\hline Draught & $82.91 \mathrm{~m}$ & $106.14 \mathrm{~m}$ \\
\hline Metacentric height & $11.32 \mathrm{~m}$ & $14.13 \mathrm{~m}$ \\
\hline Pitch angle & $4.71^{\circ}$ & $5.83^{\circ}$ \\
\hline
\end{tabular}

Table 4. Dimensions and main hydrostatic parameters for Hexafloat design.

\begin{tabular}{lcc}
\hline Hexafloat & \multicolumn{2}{c}{ Optimized Value } \\
\hline Wind turbine & NREL 5 MW & DTU 10 MW \\
\hline Central column diameter & $8.38 \mathrm{~m}$ & $14.11 \mathrm{~m}$ \\
\hline Central column height & $35.25 \mathrm{~m}$ & $35.02 \mathrm{~m}$ \\
\hline Hexagon radius & $30.00 \mathrm{~m}$ & $30.00 \mathrm{~m}$ \\
\hline Ballast distance above sea level & $99.45 \mathrm{~m}$ & $100 \mathrm{~m}$ \\
\hline Magnetite ballast mass & $3.304 \times 10^{6} \mathrm{~kg}$ & $4.542 \times 10^{6} \mathrm{~kg}$ \\
\hline Steel mass & $1.380 \times 10^{6} \mathrm{~kg}$ & $1.687 \times 10^{6} \mathrm{~kg}$ \\
\hline Material cost & $4.47 \mathrm{M} €$ & $5.52 \mathrm{M} €$ \\
\hline Draught & $23.28 \mathrm{~m}$ & $18.40 \mathrm{~m}$ \\
\hline Metacentric height & $31.61 \mathrm{~m}$ & $23.18 \mathrm{~m}$ \\
\hline Pitch angle & $3.56^{\circ}$ & $7.87^{\circ}$ \\
\hline
\end{tabular}

The optimized design for Spar-buoy and Hexafloat with a $5 \mathrm{MW}$ wind turbine is illustrated in Figure 13. 


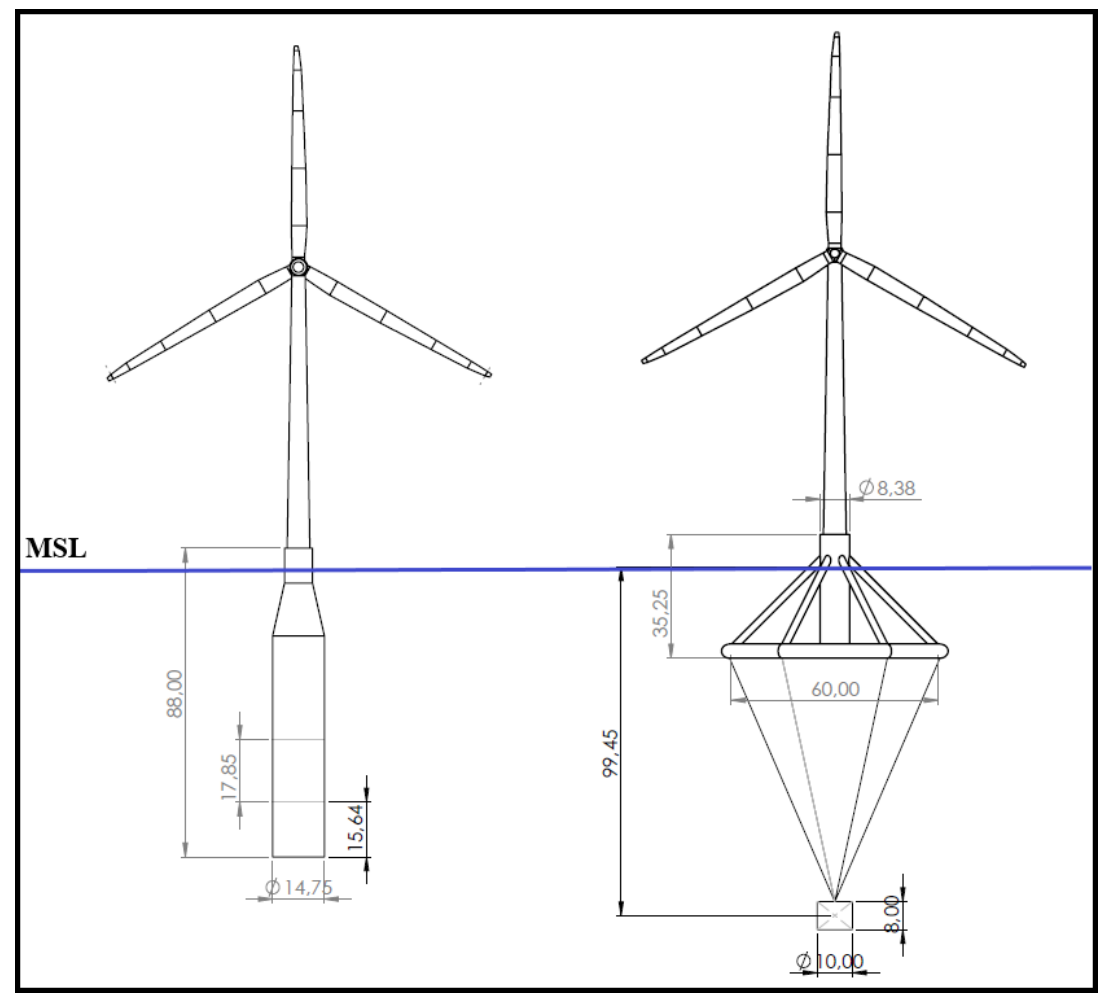

Figure 13. Cad representation of spar-buoy and Hexafloat design.

\section{Case Study_Pantelleria Island}

The goal of this study is the installation of an offshore wind farm in the Italian Mediterranean. For the preliminary study, wind availability and productivity data have been extrapolated from the database of anemometric data, which can be found on the RSE website that also prepared the wind atlas [32]. As it is shown in Figure 14, the greatest resource is available in the south of Sardinia and along Sicily channel. For geographical reasons Pantelleria island was chosen as the installation site.

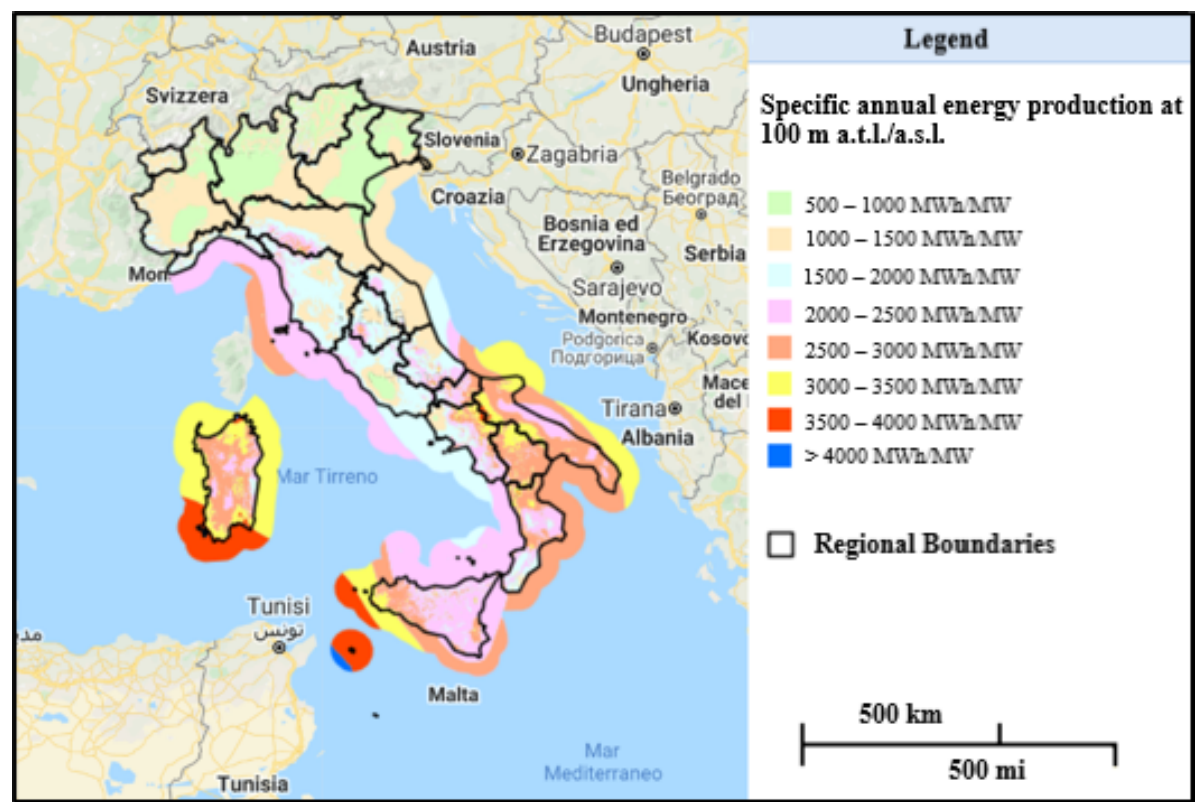

Figure 14. Wind atlas with annual energy production at $100 \mathrm{~m}$, adapted from the work in [32]. 
Pantelleria is a small Italian island located in the Sicily channel, $110 \mathrm{~km}$ southwest from Sicily and $65 \mathrm{~km}$ northeast of Tunisia, in one of the windiest areas of Italy. However, this energy potential has not yet been exploited, as there are not both onshore and offshore wind farms in the island. In fact, the electricity requirement, quantified as about $37.6 \mathrm{GWh}$ per year, is completely provided by a thermoelectric power station (Smede) and some small photovoltaic parks [33]. Consequently, as the island is not connected to the national electricity grid and electricity must be produced on site, the cost of electricity is higher than in the rest of Italy. The aim of this study is to size a small wind farm, able to completely satisfy the island's electricity needs.

\subsection{Sites Identification}

In order to identify the best site around Pantelleria, the entire area around the island within national borders was selected as the first survey. After that, hourly wind data of the last decade were obtained from the database of ERA5 ECMWF and extracted using software Qgis. Through this data, it was possible to generate the Weibull distribution and, by putting it together with the power curve of a NREL 5 MW reference wind turbine, it was possible evaluate the annual productivity of the selected area. The average sea depth for each site was obtained by EMODnet Bathymetry portal [34] . Three sites were considered, as reported in Table 5 and illustrated in Figure 15.

Table 5. Sites characteristics.

\begin{tabular}{lccc}
\hline Site & A & B & C \\
\hline Average sea depth & $120 \mathrm{~m}$ & $400 \mathrm{~m}$ & $114 \mathrm{~m}$ \\
\hline Distance from shore & $21.5 \mathrm{~km}$ & $8.5 \mathrm{~km}$ & $26.5 \mathrm{~km}$ \\
\hline Productivity [MWh/MW] & $4235 \mathrm{MWh} / \mathrm{MW}$ & $4320 \mathrm{MWh} / \mathrm{MW}$ & $4205 \mathrm{MWh} / \mathrm{MW}$ \\
\hline Coordinates & $37^{\circ} 01^{\prime} \mathrm{N}-12^{\circ} 02^{\prime} \mathrm{E}$ & $36^{\circ} 54^{\prime} \mathrm{N}-11^{\circ} 54^{\prime} \mathrm{E}$ & $36^{\circ} 37^{\prime} \mathrm{N}-11^{\circ} 48^{\prime} \mathrm{E}$ \\
\hline
\end{tabular}

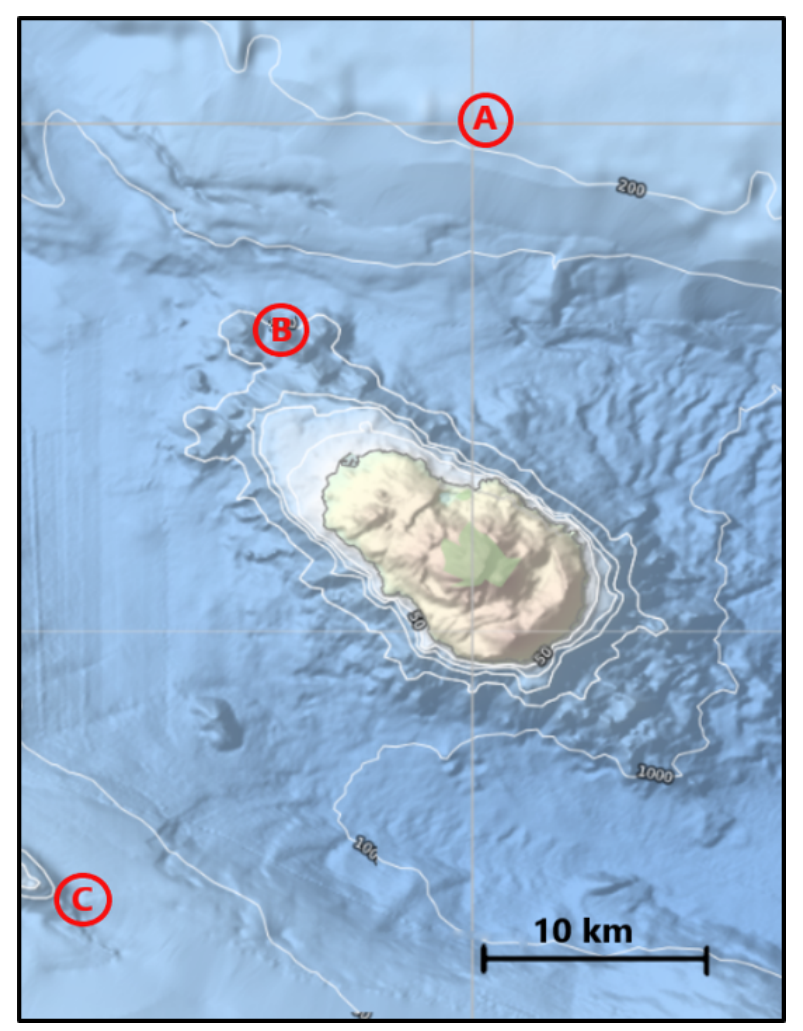

Figure 15. Pantelleria's sites. 


\subsection{Wind Farm Definition}

In this paragraph, the proposal of a wind farm is presented. The aim is to generate almost all the island's electricity needs and to release it from the use of diesel fuel, necessary for the thermoelectric power station. This would contribute to making the island energetically independent, as well as reducing polluting emissions. The study is based on the following hypotheses.

- $10 \mathrm{MW}$ wind farm, to satisfy electrical needs of $37 \mathrm{GWh}$ per year;

- two floating platforms, each of them supporting a wind turbine;

- $\quad$ use of NREL 5 MW wind turbine; and

- $\quad$ one offshore electrical substation.

The wind farm, as visible in Figure 16, is constituted by two platforms, each of which supports a NREL $5 \mathrm{MW}$ wind turbine. This turbine was used because unlike commercial turbines, all the data and fundamental dimensions are known, and the large diffusion allows comparisons with other projects and publications. Furthermore, despite the growing trend in power ratings in recent years, in the study it is considered a $5 \mathrm{MW}$ turbine for visibility reasons: the island of Pantelleria is rich in scenic beauty and some areas are subject to severe environmental constraints. The use of larger turbines would involved greater visual impact and would require greater distances from the coast; consequently, higher costs associated with the presence of marine cables.

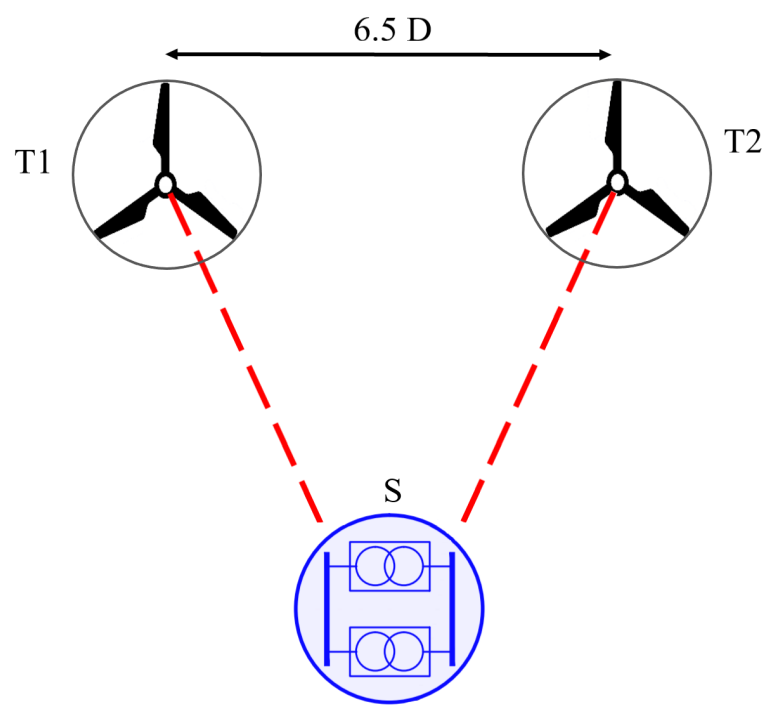

Figure 16. Wind farm layout. $\mathrm{T}$ is the wind turbine, $\mathrm{D}$ the rotor diameter and $\mathrm{S}$ the electrical substation.

The platform is moored by three catenary lines and it is anchored by three drag-embedded anchors. The length of the moorings has been considered equal to 3 times the sea-depth. The distance between each turbine is 6.5 times the rotor diameter. Two kinds of floating platform would be considered-the Spar-buoy and the Hexafloat-in the configuration optimized by genetic algorithm. As far as the electric grid is concerned, the turbines are connected to the offshore substation by array marine cables. The substation raises the electrical voltage so as to minimize losses and it is connected to the onshore substation through export cables, for the stretch along the sea, and terrestrial cables for the stretch along the coast.

\subsection{Capex and Opex Assumptions}

The Capital Expenditure (CAPEX) for an offshore wind farm is difficult to define, because of the high number of cost items, often complex to estimate. Based on the currently built projects, like HyWind Scotland and Windfloat, and studies conducted such as that of the Carbon Trust in 2015, the main cost items are relative to turbines and platforms, moorings and anchors, the balance of 
the system that includes the cost of the electrical grid and connections to shore, and installation. In particular, regarding the costs of the platform, it consists of the material cost multiplied by a form factor, which takes into account the complexity of the structure and the cost of manufacture and it is 1.1 for the spar-buoy design and 1.3 for the Hexafloat design. As moorings, simple catenaries have been considered, connected with drag-embedded anchors. Costs relating to the electrical part, such as marine cables and electrical substations, were obtained from a wind farm project in the Sicily canal, near Marsala, available on the Italian Ministry of the Environment website. The installation cost is higher for the spar design because the assembly of the turbine takes place in open sea and requires the use of large laying vessels; instead, for the semi-submersible concept, the assembly of the turbine on the platform can be done in a dry dock and the structure can be transported on site by simple tugs. Table 6 illustrates the assumptions made for each Capex item.

Table 6. Assumptions for Pantelleria's offshore wind farm.

\begin{tabular}{llll}
\hline Capex Items & Assumption & Unit of Measure & Source \\
\hline Turbine & 1.3 & {$[\mathrm{~m} € / \mathrm{MW}]$} & Life50+ project [35] \\
\hline Platform & Material cost $\cdot \mathrm{f}$ & {$[\mathrm{m} €]$} & \\
\hline Moorings & 500 & {$[£ \mathrm{~m}]$} & Carbon Trust 2015 [36] \\
\hline Anchors & 80000 & {$[€]$} & Carbon Trust 2015 [36] \\
\hline Array marine cables & 400 & {$[€ / \mathrm{m}]$} & Marsala Project [16] \\
\hline Export marine cables & 600 & {$[€ / \mathrm{m}]$} & Marsala Project [16] \\
\hline Offshore electrical substation & 0.311 & {$[\mathrm{~m} €]$} & Renewable Energy [37] \\
\hline Onshore electrical substation & 0.120 & {$[\mathrm{~m} €]$} & Renewable Energy [37] \\
\hline Terrestrial cable duct & 500 & {$[€ / \mathrm{m}]$} & Marsala Project [16] \\
\hline Installation & 2.5 (spar) 1.5 (Hexafloat) & {$[\mathrm{m} € / \mathrm{MW]}$} & Carbon Trust 2015 [36] \\
\hline Decomissioning & $2 \%$ & {$[\mathrm{~m} €]$} & Carbon Trust 2015 [36] \\
\hline
\end{tabular}

Instead, regarding the operational expenditure (OPEX), which include both maintenance and inspection costs and transmission charges, were derived from the following expression from the Carbon Trust [36], expressed in million Norwegian Kroner per megawatt hour:

$$
\text { OPEX }=0.91 \quad[M N O K / M W]
$$

\section{4. $L C O E$}

The Levelized Cost Of Energy (LCOE) in electrical energy production can be defined as the present value of the price of the produced electrical energy, usually expressed in Euros per megawatt hour, considering the economic life of the plant and the costs incurred in the construction, operation and maintenance. In other words, it is the ratio between the sum of cost over lifetime and the sum of electrical energy produced over lifetime [38]. The LCOE formula is expressed as

$$
L C O E=\frac{I_{0}+\sum_{t=1}^{n} \frac{A_{t}}{(1+i)^{t}}}{\frac{M_{e l}}{(1+i)^{t}}} \quad[€ / M W h]
$$

where $I_{0}$ is the capital expenditure in $\mathrm{m} €, A_{t}$ is the annual operating costs in year in $\mathrm{m} €, M_{e l}$ is the produced electricity in the corresponding year in MWh, $i$ is the weighted average cost of capital in \%, $n$ is the operational lifetime in years, and $t$ is the individual year of lifetime.

The produced electricity has been obtained from the productivity, estimated from Era5 database, multiplied for the nominal power. Losses were also considered: electrical losses equal to $3.6 \%$ of total and aerodynamic losses equal to $10 \%$ of total, mainly due to wake effect. Consequently, site A is 
characterized by 3764 full load hours/year, site B by 3748 full load hours/year, and site C by 3648 full load hours/year. The operational lifetime is 25 years, while for the WACC an $8 \%$ value has been considered, as suggested from The Offshore Wind Outlook 2019 [2].

In the following Figure 17, the main results about Capex and LCOE are reported.

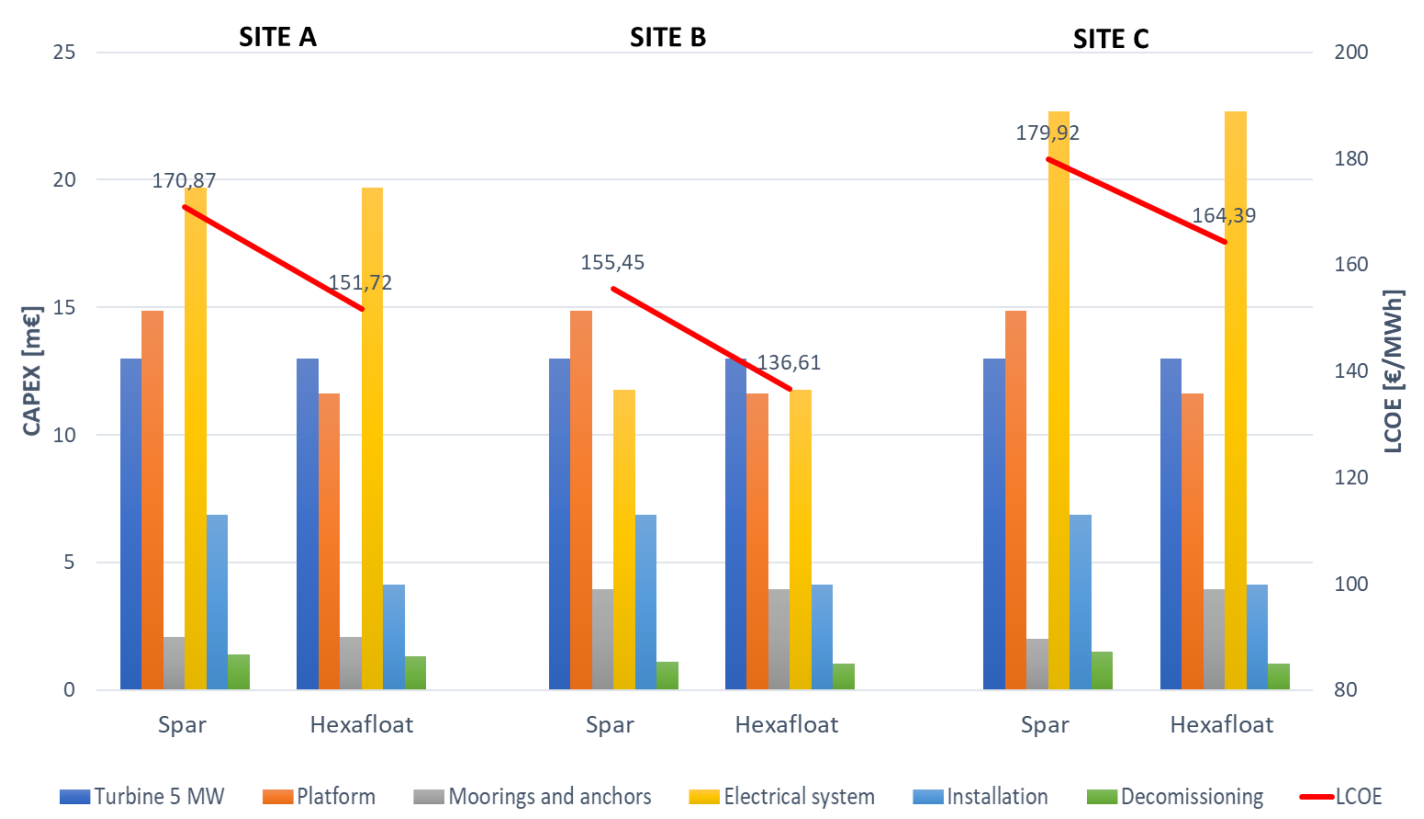

Figure 17. Capex and LCOE for sites A, B, and C, considering spar-buoy and Hexafloat optimized concepts.

Regarding site A, which is $21.5 \mathrm{~km}$ far from the cost, the most relevant cost item is the electrical system for both platforms. Moreover, the most competitive platform is the Hexafloat, and it is economically more convenient for the platform material and installation costs than the spar-buoy. This is also true for the site $\mathrm{B}$ : in this case, the electrical system cost is inferior because it is only $8.5 \mathrm{~km}$ far from the coast and marine cables are less impacting in total Capex. Finally, site $\mathrm{C}$ has a greater LCOE among the three sites, as it is similar to site A for the depth of the sea, but has a greater distance from the coast.

Overall, the value of the LCOE is quite high when compared with other offshore wind projects, as reported in [36]. This is mainly related to two different aspects:

- the presence of very high fixed costs, related to electrical system and cables, and

- the use of only two wind turbines, which do not allow amortization of fixed costs.

\section{Sensitivity Analysis}

In the following paragraph a sensitivity analysis is carried out. In particular, the influence of capacity factor, WACC and of the number of wind turbines is analyzed for each site and kind of platform.

\subsection{Influence of Capacity Factor}

The Capacity Factor is the ratio of the average power generated to the rated power produced, considering the same time duration, usually one year [38]:

$$
C F=\frac{\text { Average power generated }}{\text { Rated power generated }} \quad[\%]
$$


As reported in Offshore Wind Outlook [2], in 2019 the average global capacity factor for offshore wind turbines was $33 \%$. Thanks to the use of larger turbines and made with more suitable materials, new offshore wind projects are expected to have capacity factors of over $40 \%$ in moderate wind conditions and over $50 \%$ in areas with high quality wind resources. Figure 18 shows the LCOE trend as the capacity factor varies.
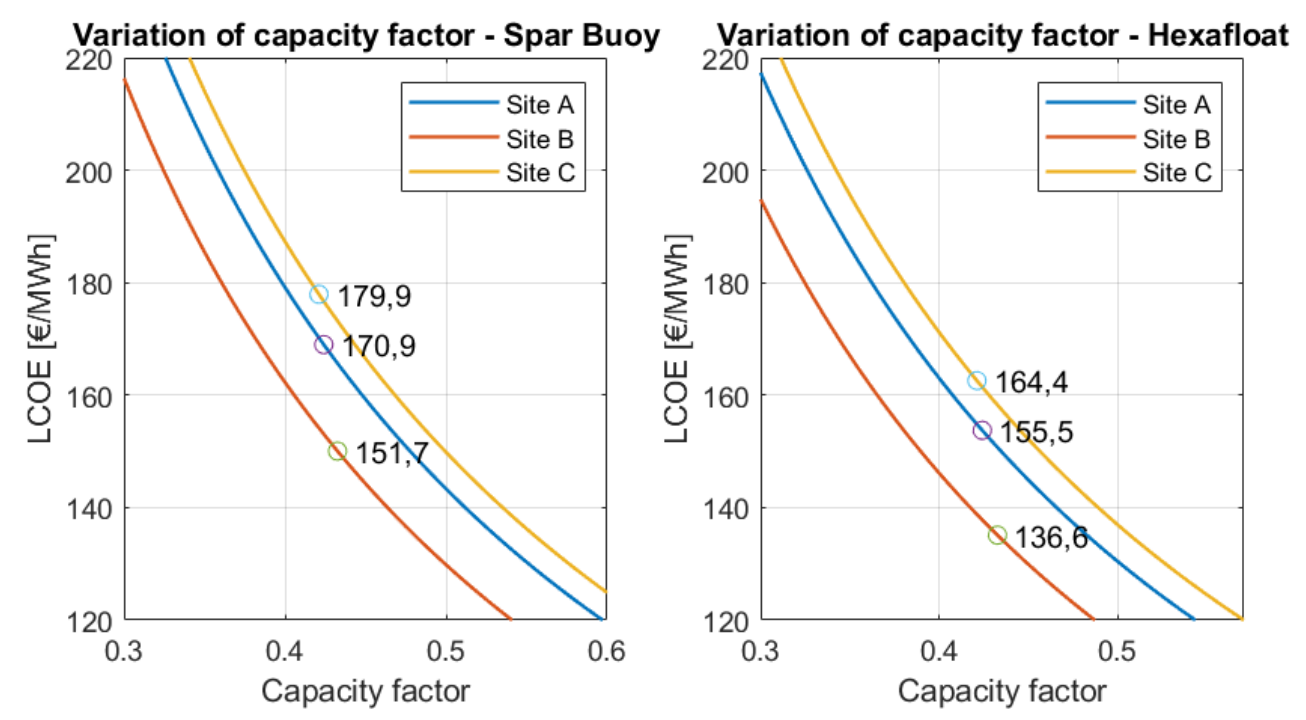

Figure 18. Influence of Capacity Factor for sites A, B, and C for both concepts.

The island of Pantelleria is located in one of the windiest areas of Italy, characterized by high productivity at $100 \mathrm{~m}$. In fact, capacity factors are respectively $42.0 \%, 42.8 \%$, and $41.7 \%$ for sites A, B, and $\mathrm{C}$. It is possible to increase the capacity factor value by using more performing turbines.

\subsection{Influence of WACC}

The Weighted Average Capital Cost (WACC) is a financial metric used to measure the cost of capital to a firm:

$$
W A C C=W_{e} K_{e}+W_{d} K_{d}(1-t) \quad[\%]
$$

where $W_{e}$ is the percentage of financing from equity, $K_{e}$ is the cost of equity, $W_{d}$ is the percentage of financing from debt, $K_{d}$ is the cost of debt, and $t$ is the corporate tax rate. The WACC is an indicator of the riskiness of an investment.

The Offshore Wind Outlook [2] suggests an 8\% WACC in advanced economies, decreasing to $4 \%$ in 2040. As shown in Figure 19, the WACC has an important role in the determination of LCOE: a decrease in the WACC would allow significantly lower investment costs. 

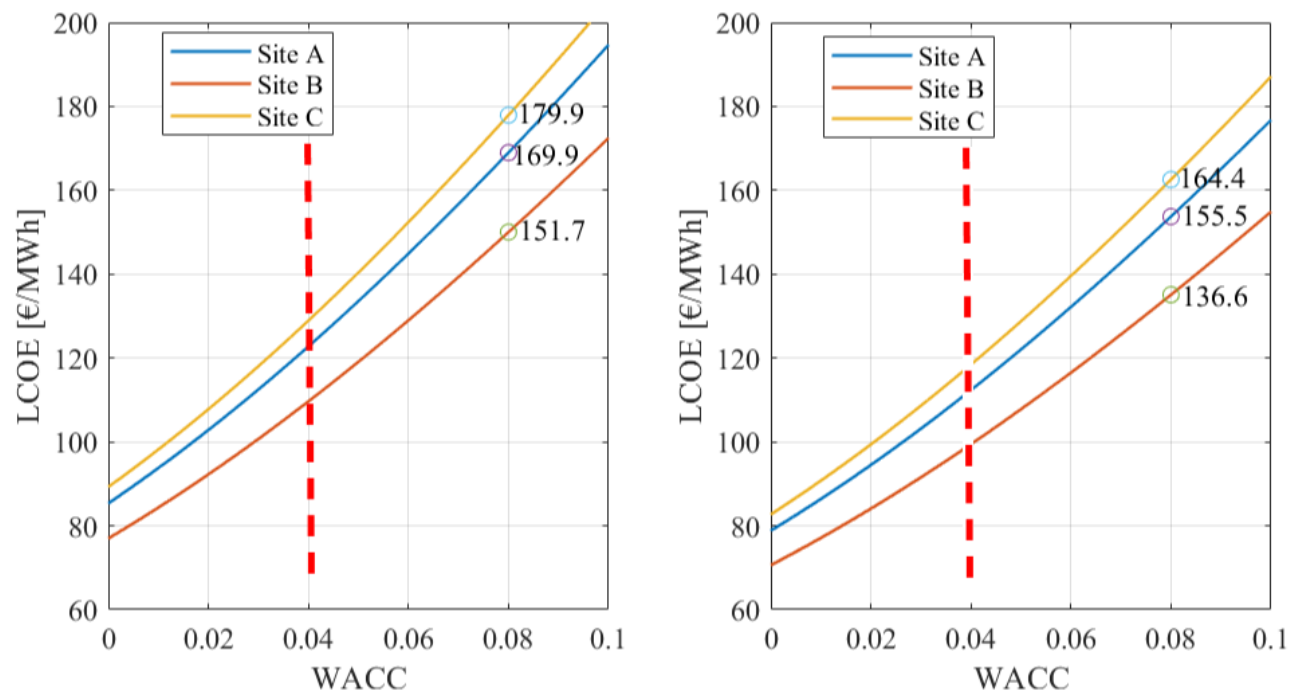

Figure 19. Influence of WACC for sites A, B, and C for both concepts.

\subsection{Influence of Number of Wind Turbines}

As it was shown by the composition of the capital expenditure, the electrical costs, which include marine cables, and offshore and onshore substations, are the most relevant part of fixed costs. Consequently, as it is shown in Figure 20, as the number of turbines increases, LCOE decreases.
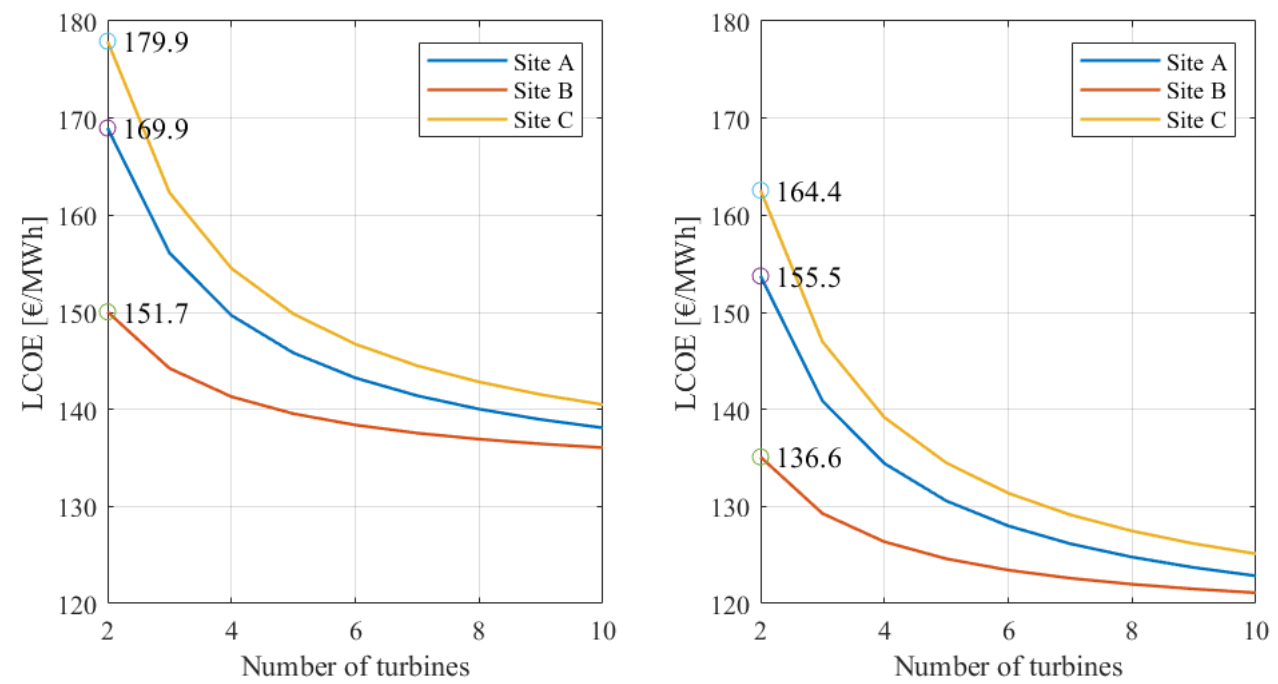

Figure 20. Influence of number of turbines for sites A, B, and C for both concepts.

In particular, if the number of turbines was 5, roughly all the island's energy needs, estimated at around $80 \mathrm{GWh}$ per year, would be met, with a clear decrease in the LCOE compared to the case study of 2 wind turbines.

\subsection{Comparison between $5 \mathrm{MW}$ and $10 \mathrm{MW}$ Wind Turbines}

In this paragraph LCOE is compared with the variation of the turbine rating. Two wind turbines have been considered: the NREL $5 \mathrm{MW}$ and the DTU $10 \mathrm{MW}$. The use of the $10 \mathrm{MW}$ turbine allows, with the same nominal power, to save in terms of number of platforms and consequently the LCOE is lower for both the concepts. In the following figure, the comparison is reported only for site A, as a similar trend is found in the other sites. 

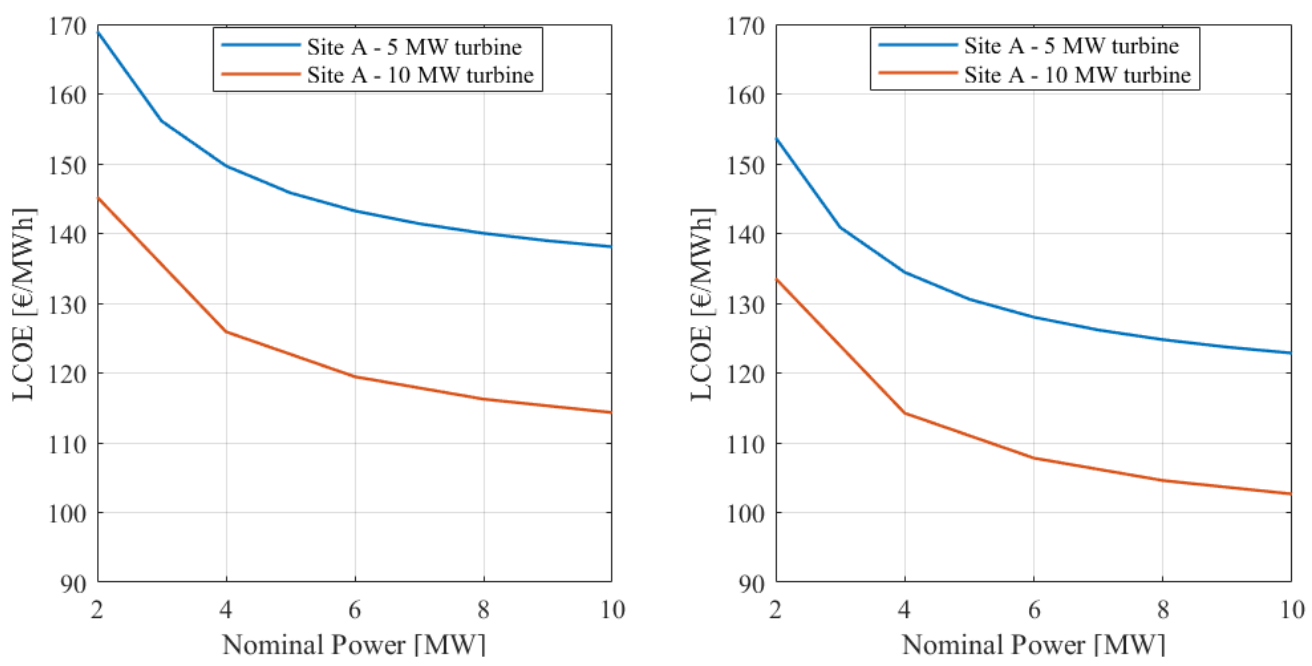

Figure 21. Comparison between $5 \mathrm{MW}$ and $10 \mathrm{MW}$ wind turbine for site $\mathrm{A}$.

In Figure 21 it is observed that the curve of the LCOE for the larger turbine (10 MW) is always below the smaller one ( $5 \mathrm{MW}$ ). The use of larger turbines reduces the number of platforms, has a greater visual impact, and cannot be used for sites near the island.

\subsection{Cost Reduction and LCOE Future Trend}

In this paragraph, LCOE trend is investigated due to possible cost reduction in next years. As reported in [39], for a median scenario in 2030, the following drivers for cost reduction are considered: Capex reduction equal to $5 \%$, Opex reduction equal to $8 \%$, and WACC reduction equal to $5 \%$. Instead, the Capacity Factor is expected to grow by $9 \%$ and the project life by $25 \%$. These considerations, applied to estimate the LCOE of each site of Pantelleria, have been compared with European LCOE trend of the Offshore Wind Outlook 2019 [2], as reported in Figure 2.

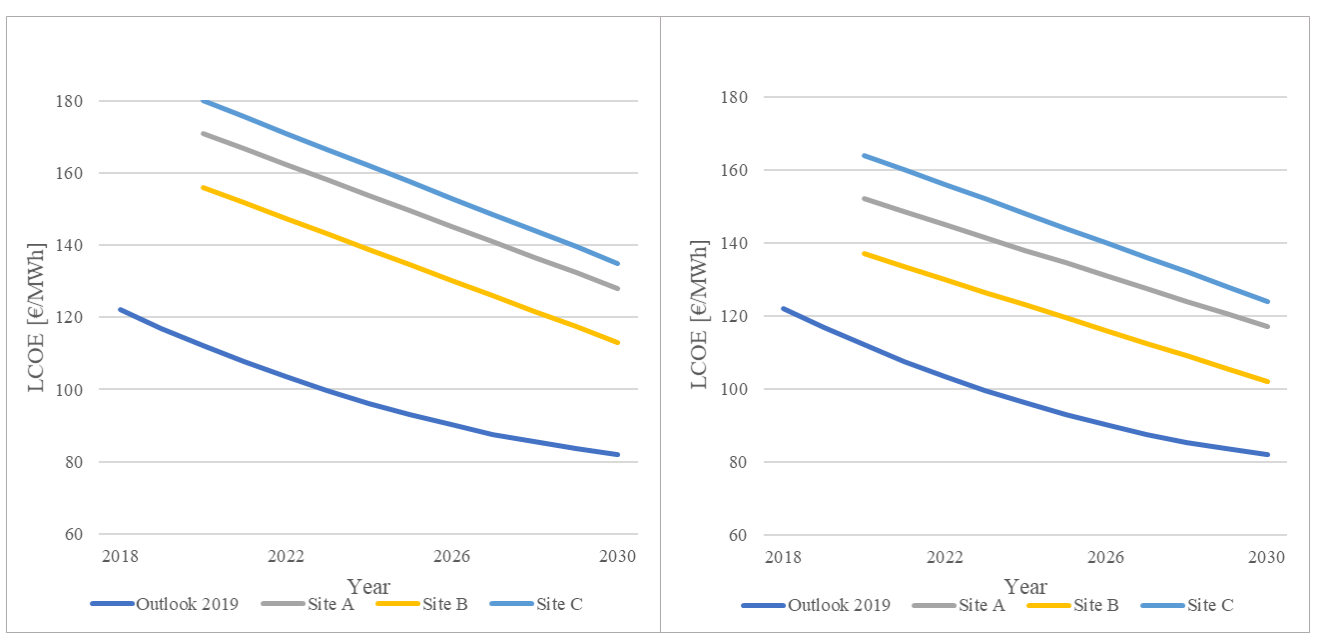

Figure 22. Levelized Cost Of Energy (LCOE) decrease due to cost reduction for Spar-buoy (left) and Hexafloat (right).

In Figure 22 it is observed that the LCOE curve, estimated by the Outlook, in blue, is always below the curves of the Pantelleria wind farm for all sites. This is due to many reasons: first of all, the Outlook considers every kind of offshore wind farm, not only floating, but also bottom-fixed, that are more widespread in Europe. Second, wind farms with dozens of wind turbines were also taken into 
consideration. However, the Hexafloat structure is the one that comes closest to these estimates, in particular for site B.

\section{Conclusions}

The purpose of this work was to highlight the importance of choosing the platform in a wind farm project, in order to pursuit lower investment costs. One of the possible solutions consists in defining structures that minimize dimensions and the quantity of material required, typically steel, ensuring the constraints imposed by Standards. In particular, as seen in the Pantelleria case study, a structure like Hexafloat, smaller than traditional spar-buoy concept or Windfloat semi-submersible, as well as having smaller global dimensions which facilitate construction in the dry-dock and transport to the site, lends itself better to a standardization, as it is easily scalable, and a possible diffusion in the Mediterranum Sea. This would allow the construction of a wind farm capable of supplying the island's energy needs and making it independent from the use of fossil fuels. Site B represents the best site reference: it has the best LCOE of all three sites, but it has the drawback of being particularly close to the coast, where it could cause moderate visual polluting. The most promising floating platform is the Hexafloat. As regards LCOE, these are higher values, if compared with the estimates of the offshore wind, also partly due to the isolated position of the island and due to the presence of only two wind turbines. However, in the next few years the decrease of many Capex cost items and the evolution of the offshore wind market, will make this technology even more competitive.

Author Contributions: Conceptualization, A.G.; methodology, A.G.; software, A.G.; validation, A.G.; formal analysis, A.G.; investigation, A.G.; resources, L.C. and R.C.; data curation, A.G.; writing-review and editing, A.G.; visualization, G.B., L.C., and R.C.; supervision, G.B. and G.M. All authors have read and agreed to the published version of the manuscript.

Funding: This research received no external funding.

Conflicts of Interest: The authors declare no conflict of interest.

\section{Abbreviations}

The following abbreviations are used in this manuscript.

$\begin{array}{ll}\text { CAPEX } & \text { Capital Expenditure } \\ \text { COB } & \text { Center of Bouyancy } \\ \text { COG } & \text { Center of Gravity } \\ \text { DNVGL } & \text { Det Norske Veritas Germanischer Lloyd } \\ \text { DTU } & \text { Danmarks Tekniske Universitet } \\ \text { EMODnet } & \text { European Marine Observation and Data Network } \\ \text { FOWT } & \text { Floting Offshore Wind Turbine } \\ \text { GA } & \text { Genetic Algorithm } \\ \text { GM } & \text { Metacentric Height } \\ \text { LCOE } & \text { Levelized Cost of Energy } \\ \text { MSL } & \text { Mean Sea Level } \\ \text { NREL } & \text { National Renewable Energy Laboratory } \\ \text { OPEX } & \text { Operational Expenditure } \\ \text { PNIEC } & \text { Integrated National Energy and Climate Plan } \\ \text { RSE } & \text { Ricerca Sistema Energetico } \\ \text { TLP } & \text { Tension Leg Platform } \\ \text { TRL } & \text { Technology Readiness Level } \\ \text { WACC } & \text { Weighted Average Capital Cost }\end{array}$




\section{References}

1. Wind Europe. Wind Energy in Europe in 2019. 2020. Available online: https://windeurope.org/aboutwind/statistics/european/wind-energy-in-europe-in-2019/ (accessed on 10 October 2020).

2. International Agency Organization (IEA). Offshore Wind Outlook 2019. 2019. Available online: https:/ / webstore.iea.org/offshore-wind-outlook-2019-world-energy-outlook-special-report (accessed on 10 October 2020).

3. Wind Europe. Offshore Wind in Europe. 2020. Available online: https://windeurope.org/ (accessed on 10 October 2020).

4. Wind Europe. Our Energy, Our Future: How Offshore Wind Will Help Europe Go Carbon-Neutral. 2019. Available online: https:/ / windeurope.org/about-wind/reports/our-energy-our-future/ (accessed on 12 October 2020).

5. International Renewable Energy Agency (IRENA). Future of Wind: Deployment, Investment, Technology, Grid Integration and Socio-Economic Aspects. 2019. Available online: https:/ /irena.org/-/media/Files / IRENA/Agency/Publication/2019/Oct/IRENA_Future_of_wind_2019.pdf (accessed on 12 October 2020).

6. DTU Wind Energy. Global Wind Atlas. Available online: https://globalwindatlas.info/ (accessed on 5 September 2020).

7. Myhr, A.; Bjerkseter, C.; Ågotnes, A.; Nygaard, T.A. Levelised cost of energy for offshore floating wind turbines in a life cycle perspective. Renew. Energy 2014, 66, 714-728. [CrossRef]

8. Equinor, HyWind Scotland, The World's First Commercial Floating Wind Farm. Available online: https:/ / www.equinor.com/en/what-we-do/floating-wind.html (accessed on 15 October 2020).

9. EDP Energias de Portugal. WindFloat Atlantic Project. Available online: https://www.edp.com/en/ innovation/windfloat (accessed on 15 October 2020).

10. Ideol Offshore, École Centrale de Nantes. Demonstration and Benchmarking of a Floating Wind Turbine System for Power Generation in Atlantic Deep Waters. Available online: https:/ / floatgen.eu/ (accessed on 15 October 2020).

11. Ideol Offshore. A Pre-Commercial Project of 3 Units: EOLMED Project. Available online: https://www. ideol-offshore.com/en/eolmed-project (accessed on 16 October 2020).

12. Engie, EDP Renewables. Floating Wind Turbines of the Gulf of Lion. Available online: https://info-efgl.fr/ le-projet/ (accessed on 16 October 2020).

13. EDF Renouvelables. Provence Grand Large. Available online: https://www.provencegrandlarge.fr/wpcontent/uploads/2019/02/09-FICHE-PGL-EDF-RE-2018-BD.pdf (accessed on 16 October 2020).

14. Italian Ministry of Economic Development; Italian Ministry of the Environment and Land and Sea Protection; Italian Ministry of Infrastructure and Transport. Integrated National Energy and Climate Plan. 2019. Available online: https:/ / ec.europa.eu/energy/sites/ener/files/documents/it_final_necp_main_en.pdf (accessed on 5 October 2020).

15. Italian Ministry of the Environment and Land and Sea Protection. Wind Farm in the Anchorage Outside the Port of Taranto. Available online: https://va.minambiente.it/en-GB/Oggetti/Info/299 (accessed on 5 October 2020).

16. Italian Ministry of the Environment and Land and Sea Protection. Environmental Evaluations and Authorizations: Project for the Construction of a Floating Offshore Wind Farm in the Sicilian Channel, Consisting of 25 Turbines Each with a Nominal Power of $10 \mathrm{MW}$, for a Total Power of 250 MW. Available online: https:/ / va.minambiente.it/it-IT/Oggetti/Documentazione/7273/10503\#collapse (accessed on 5 October 2020).

17. Italian Ministry of the Environment and Land and Sea Protection. Floating Offshore Wind Farm Plant Project for the Production of Electricity from Renewable Wind Sources Consisting of 42 Wind Turbines Each with a Nominal Power of 12 MW for a Total Power of the Plant of 504 MW. Available online: https:/ / va.minambiente.it/en-GB/Oggetti/Info/7505 (accessed on 5 October 2020).

18. Hannon, M.; Topham, E.; MacMillan, D.; Dixon, J.; Collu, M. Offshore Wind, Ready to Float? Global and UK Trends in the Floating Offshore Wind Market; University of Strathclyde: Glasgow, UK, 2019.

19. Fincantieri Offshore: Sea Flower Platform. Available online: https://www.fincantierioffshore.it/sea-flower. html (accessed on 8 September 2020). 
20. Roddier, D.; Cermelli, C.; Weinstein, A. Windfloat: A floating foundation for offshore wind turbines. Part 1: Design basis and qualification process. In Proceedings of the ASME 28th International Conference on Ocean, Offshore and Arctic Engineering, Honolulu, HI, USA, 31 May-5 June 2009.

21. Delahaye, T.; Franc, P.; Colmard, C.; Gentil, F. New Pendular Floater for Offshore Wind Commercial Farms. In Proceedings of the Offshore Mediterranean Conference and Exhibition, Ravenna, Italy, 27-29 March 2019.

22. Interreg North West Europe; Saipem, S.A. AFLOWT Project: Basis of design. In Proceedings of the Offshore Mediterranean Conference and Exhibition, Ravenna, Italy, 27-29 March 2019.

23. Huber, F. The first floating wind turbines. In Proceedings of the 2nd International Conference on Ocean Energy (ICOE 2008), Brest, France, 15-17 October 2008.

24. Techet, A.H. Hydrodynamics for Ocean Engineers; MITPRESS: Cambridge, MA, USA, 2004.

25. DNVGL Offshore Standarts. DNVGL-OS-C301: Stability and Watertight Integrity. 2020. Available online: https: / /rules.dnvgl.com/docs/pdf/DNVGL/OS/2020-07/DNVGL-OS-C301.pdf (accessed on 8 October 2020).

26. Hansen, M.O.L. 1-D Momentum Theory for an Ideal Wind Turbine. In Aerodynamics of Wind Turbines; Earthscan Publishing House: Sterling, VA, USA, 2008; pp. 38-46.

27. MathWorks. Global Optimization Toolbox. 2020. Available online: https://it.mathworks.com/help/gads/ index.html?s_tid=CRUX_lftnav (accessed on 12 October 2020).

28. Sandner, F.; Wie, F.Y.; Matha, D.; Grela, E.; Azcona, J.; Munduate, X.; Voutsinas, S.; Natarajan, A. Deliverable D4.33-Innovative Concepts for Floating Structures. InnWind.EU 2014, 10, 11-31.

29. Statista.com: Iron Ore Prices from June 2019 to June 2020. Available online: https: / /www.statista.com/ statistics/300419/monthly-iron-ore-prices / (accessed on 10 October 2020).

30. DNVGL Offshore Standarts. DNVGL-ST-0119: Floating Wind Turbine Structures. 2018. Available online: https://rules.dnvgl.com/docs/pdf/DNVGL/ST/2018-07/DNVGL-ST-0119.pdf (accessed on 12 October 2020).

31. Collu, M.; Borg, M. Design of floating offshore wind turbines. In Offshore Wind Farms: Technologies, Design and Operation; Elsevier: Amsterdam, The Netherlands, 2016; pp. 359-385. [CrossRef]

32. RSE. Interactive Wind Atlas. Available online: http://atlanteeolico.rse-web.it/index-en.phtml (accessed on 10 September 2020).

33. PAES (Sustainable Energy Action Plan). Available online: http://www.smartisland.eu/replicabilita/ pantelleria.html (accessed on 10 September 2020).

34. EMODnet Bathymetry. Available online: https://www.emodnet.eu/bathymetry (accessed on 5 October 2020).

35. Benveniste, G.; Lerch, M.; De Prada, M.; Kretschmer, M.; Berqué, J.; López, A.; Pérez, G. Qualification of innovative floating substructures for $10 \mathrm{MW}$ wind turbines and water depths greater than $50 \mathrm{~m}$-Deliverable 2.2. LCOE tool description, technical and environmental impact evaluation procedure. LIFES50+ 2016, 10, $50-53$.

36. James, R.; Costa Ros, M. Floating Offshore Wind: Market and Technology Review; Carbon Trust: London, UK, 2015; pp. 79-93.

37. Johnston, B.; Foley, A.; Doran, J.; Littler, T. Levelised cost of energy, A challenge for offshore wind, Renewable Energy. Renew. Energy 2020. [CrossRef]

38. Pecher, A.; Peter Kofoed, J. Economics of WECs. In Handbook of Ocean Wave Energy; Springer: Berlin/Heidelberg, Germany, 2017; pp. 119-136.

39. Wiser, R.; Jenni, K.; Seel, J.; Baker, E.; Hand, M.; Lantz, E.; Smith, A. Forecasting Wind Energy Costs and Cost Drivers: The Views of the World's Leading Experts; IEA Wind Task 26; IEA Wind: Olympia, WA, USA, 2016.

Publisher's Note: MDPI stays neutral with regard to jurisdictional claims in published maps and institutional affiliations.

(C) 2020 by the authors. Licensee MDPI, Basel, Switzerland. This article is an open access article distributed under the terms and conditions of the Creative Commons Attribution (CC BY) license (http://creativecommons.org/licenses/by/4.0/). 